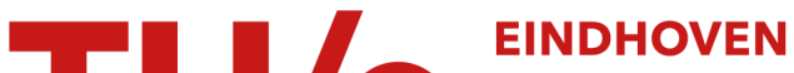 \\ UNIVERSITY OF \\ TECHNOLOGY
}

\section{The role of theoretical and mathematical modeling in scale-up}

Citation for published version (APA):

Kerkhof, P. J. A. M. (1994). The role of theoretical and mathematical modeling in scale-up. Drying Technology, 12(1-2), 1-46. https://doi.org/10.1080/07373939408959948

DOI:

10.1080/07373939408959948

Document status and date:

Published: 01/01/1994

\section{Document Version:}

Publisher's PDF, also known as Version of Record (includes final page, issue and volume numbers)

\section{Please check the document version of this publication:}

- A submitted manuscript is the version of the article upon submission and before peer-review. There can be important differences between the submitted version and the official published version of record. People interested in the research are advised to contact the author for the final version of the publication, or visit the $\mathrm{DOI}$ to the publisher's website.

- The final author version and the galley proof are versions of the publication after peer review.

- The final published version features the final layout of the paper including the volume, issue and page numbers.

Link to publication

\section{General rights}

Copyright and moral rights for the publications made accessible in the public portal are retained by the authors and/or other copyright owners and it is a condition of accessing publications that users recognise and abide by the legal requirements associated with these rights.

- Users may download and print one copy of any publication from the public portal for the purpose of private study or research.

- You may not further distribute the material or use it for any profit-making activity or commercial gain

- You may freely distribute the URL identifying the publication in the public portal.

If the publication is distributed under the terms of Article 25fa of the Dutch Copyright Act, indicated by the "Taverne" license above, please follow below link for the End User Agreement:

www.tue.nl/taverne

Take down policy

If you believe that this document breaches copyright please contact us at:

openaccess@tue.nl

providing details and we will investigate your claim. 


\title{
THE ROLE OF THEORETICAL AND MATHEMATICAL MODELLING IN SCALE-UP
}

\author{
Piet J.A.M. Kerkhof
}

(Laboratory for Chemical Process Engineering, Department of Chemical Engineering, Eindhoven University of Technology, P.O. Box 513, $5600 \mathrm{MB}$ Eindhoven, the Netherlands)

keywords and phrases : biomaterials, diffusion, fluid bed drying, foods, heat \& mass transfer, modelling, simulation, spray - drying,

\begin{abstract}
Drying processes are complex because of the non-linearity of physical phenomena and of the distributed parameter character on many levels of consideration. At different scales the relative importance of phenomena will differ. A discussion of the level structure is presented and the concept of "critical grain size" is introduced. As a general criterion for the importance of particle diffusion resistance a modified Biot-number is defined. Theoretical models are treated for diffusional mass transfer, both rigorous and short-cut models. The integration of these models with approximating relations or models for specific drying processes is demonstrated for spray drying of foods and fluidized bed drying of bioproducts. Also a theoretical treatment of several quality aspects is given.
\end{abstract}

\section{INTRODUCTION}

Scaling up of drying processes is for many driers and products still largely a matter of empiry, supported by some processing rules of thumb, and a yery sound knowledge of drier construction. Difficulties are especially met in scaling up processes for performance products, such as foods and bioproducts. In a previous paper [1], we have devoted attention to the interface and knowledge transfer problems between food producers, 
equipment manufacturers and scientists. As basic problem we have the difficulty of integration of the three areas of expertise : product knowledge, equipment building and process insight. Another problem is the difficulty or impossibility for many companies to have all expertise within their organisation. As a partial remedy we see the incorporation of theoretical models into simulation packages, to be used on PC's, along with sufficient insight into the backgrounds of the process. It is the intention of this paper to treat some basic aspects of drying problems, and show by examples in spray drying and fluid-bed drying what additional advantages can be obtained from theoretical and mathematical models.

\section{BASIC CONSIDERATIONS OF DRYING PROCESSES}

\section{Complicating factors}

From a viewpoint of quantitative understanding drying processes have the following special difficulties :

- the physical processes are highly non - linear

- there are quite complicated exchange and interaction processes

- the dominating phenomena depend on drying conditions, and may change within the course of drying.

The non - linearity is illustrated in Figs. 1 - 3. In Fig.1 the saturated water

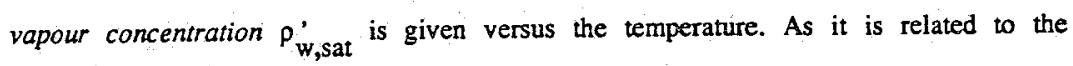
water vapour pressure by :

$P_{w, s a t}^{\prime}=\frac{p_{w}^{s} M_{w}}{R T}$

it varies very strongly with temperature. The second non - linearity is the water vapour sorption isotherm, as illustrated in Fig. 2 for aqueous maltodextrin solutions. Since at the drying surface the actual water vapour concentration is given by :

$\rho_{\mathrm{w}}^{\prime *}=a_{\mathrm{w}} \rho_{\mathrm{w}, \mathrm{sat}}^{\prime}$

the evaporation potential from the interface is strongly influenced by the water activity, 


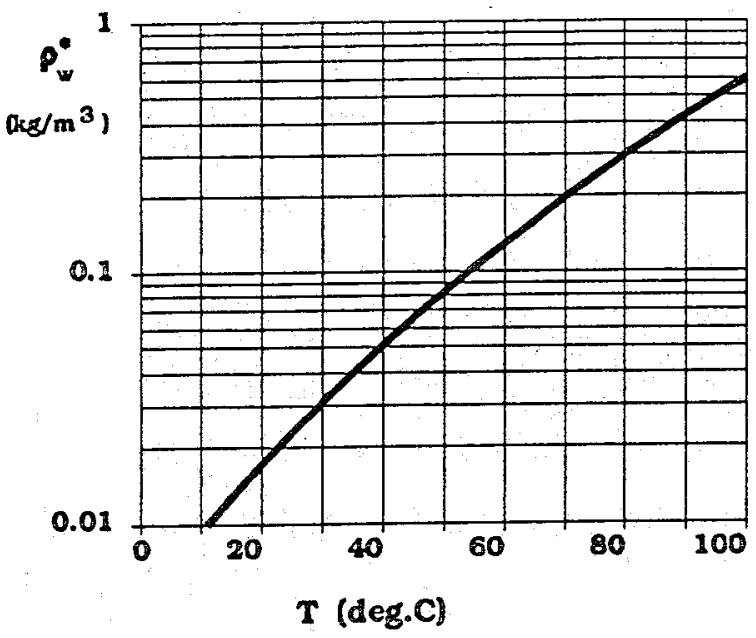

Fig1 Saturated water vapour concentration as a function of temperature

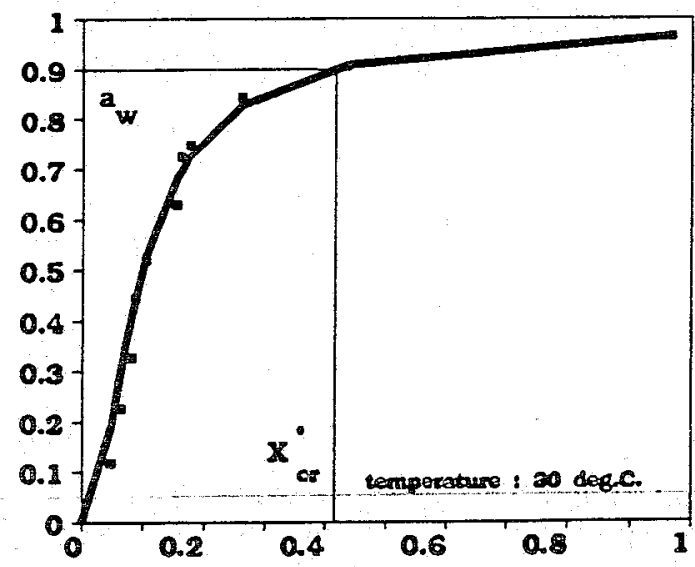

Xw $\mathrm{kg} \mathrm{w/K8}$ ds)

Fig. Water vapour sorption isotherm of aqueous matrodextrin solutions 


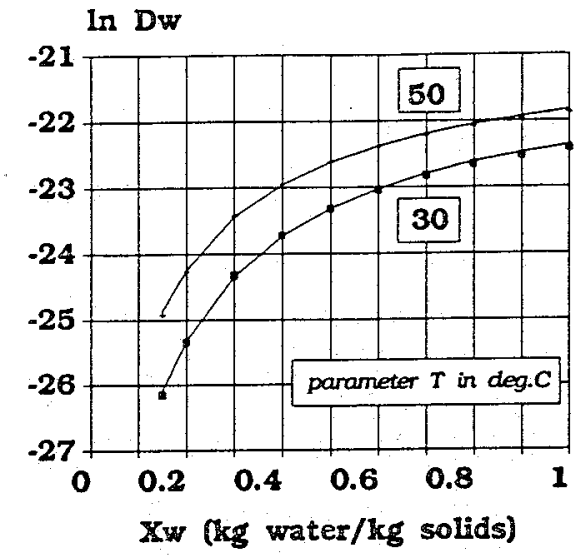

Fig.3. Molecular diffusion coefficient of water in skim - milk

which may be assumed to be in equilibrium with the moisture content at the product side of the interface.

A third non-linear factor is formed by the transport properties inside the material, as they depend on water concentration and temperature. An example is given in Fig. 3, in which the molecular diffusion coefficient of water in skim - milk is given vs. the water concentration for two temperatures. For other materials the goveming transport phenomena may be more complicated, e.g. capillary flow and vapour diffusion. Shrinkage may lead to changes in surface area; this should be accounted for depending on the isotropy [2].

The complexity of exchange processes is illustrated in a simple example of an exchange scheme in Fig. 4 for convective driers. Elements of drying material may obtain heat directly from the world outside the drier by means of conduction or various forms of radiation, but will exchange mass and heat generally with their direct micro-environment, again by various transport phenomena. The micro - environment in tum will exchange mass and heat with a larger part of the drier through convection and turbulent mixing. The macro - environment exchanges heat and mass with the extemal world.

In a still largely simplified interaction scheme for the spray drying of liquid foods [1], as shown in Fig. 5, it is clear that next to exchange of heat and mass many more interactions are present. These may be of a micro-scale nature, e.g. drying rate and degradation reactions in a given droplet, but also of macro-scale nature, e.g. the outlet 


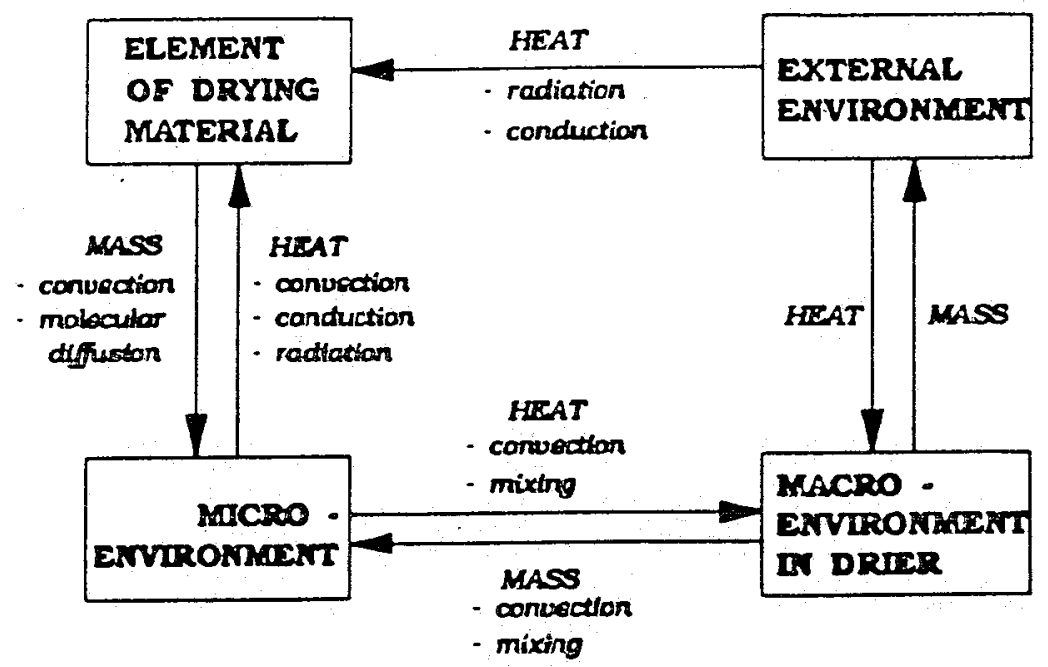

Fig.4. Diagram of heat and mass transfer mechanisms in drying

temperature dependence on overall drying rate for a given chamber size and particle size distribution. In fact the latter leads to micro-macro scale interactions : the droplets see the local temperature and humidity, the air sees all droplets.

When looking at drying processes in this way one sees many variables; the large number of interrelations however reduces considerably the number of variables one can choose, the number of degrees of freedom is very limited. Putting in too many fixed desires for a design may even decrease the number of choosable variables below zero, meaning that the overspecified problem cannot be solved.

One of the basic roles of modelling is to include the significant interrelations and physical-phenomena, and from this set make predictions for different circumstances.

Controlling regimes for the drying rate : the modified Biot - number

One of the key factors in drying processes is to describe the limiting or controlling mechanisms for the drying rate. We can do this in a quite general way for convection 


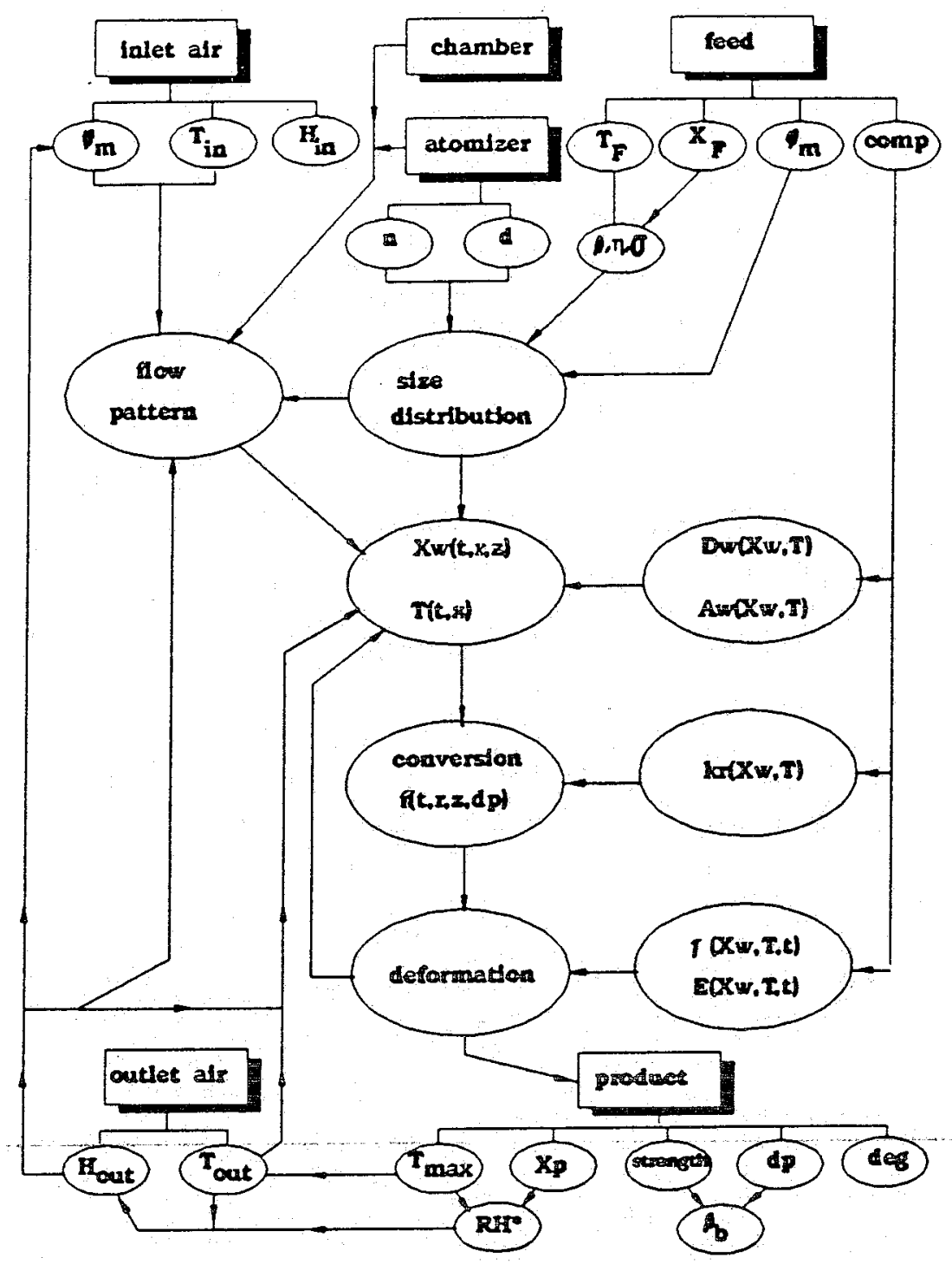

Fig.5. Diagram of some influences in spray drying of foods 
drying. Normally we start with a moisture content $X_{0}$ at which the water activity is still close to one. The rate of drying is then determined by the external heat and mass transfer coefficients and the local air temperature and humidity. The drying rate will start to fall once the-water activity at the interface decreases considerably; a practical measure is a critical value of $a_{w}=0.90$. Now we can locate our drying process between two extreme situations. In one situation, slow drying, the moisture inside has been able to diffuse fast enough, and so the water concentration inside the material is virtually flat. In that case the average moisture content $X$ is equal to the surface moisture content, and the overall critical water content equals the limiting critical water content, following from the isotherm. In fast drying, or sharp drying, the diffusion of moisture inside cannot keep up with the extemal removal, and concentration profiles are built up inside the drying material. Consequently the average critical water content will then be higher than the limiting critical water content. We can expand this consideration to the falling rate period as well. When internal diffusion can keep up with external removal of water, the product water content remains homogeneously distributed, and the water activity at the surface decreases according to the sorption isotherm values corresponding to the average moisture content; the process is externally controlled. In sharp drying the surface water concentration drops off rapidly and it is the internal rate of diffusion which determines the drying rate : the process is now internally controlled.

As a yardstick for the controlling resisitance we here propose to use a modified Biot - number, defined as :

$$
B i=\frac{k_{g, \text { eff }} L \rho_{w g}^{s}}{D_{\text {eff }} \rho_{s} x_{c r}^{*}}
$$

Here $k_{g, e f f}$ is the effective mass transfer coefficient $[\mathrm{m} / \mathrm{s}]$, in which macroscopic effects have been included. For a fluid bed this means that the increase in humidity of the drying air upon passage has been taken into account. The dimension of the product particle is $\mathrm{L}$ $[\mathrm{m}], \rho_{\mathrm{wg}}^{s}$ is the saturation vapour concentration $\left[\mathrm{kg} / \mathrm{m}^{3}\right], \mathrm{D}_{\text {eff }}$ is the effective diffusion coefficient $\left[\mathrm{m}^{2} / \mathrm{s}\right]$, and $\rho_{s}$ is the concentration of solids $\left[\mathrm{kg} / \mathrm{m}^{3}\right]$. A high value of $\mathrm{Bi}$ now indicates that in the falling rate period the main resistance lies inside the drying material, a low value that the drying rate will be externally controlled. This is illustrated in Fig. 6. We roughly place the boundary between the regions at $\mathrm{N}_{\mathrm{Bi}}=1$. As an example we consider a droplet of $100 \mu \mathrm{m}$ of a carbohydrate solution in a spray drier, 

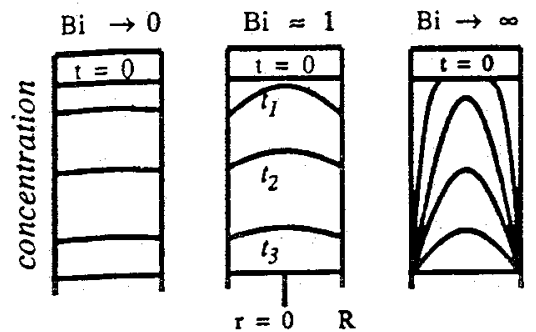

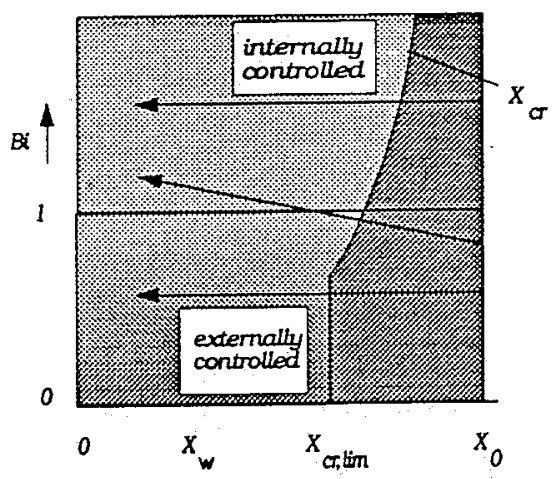

Fig.6. Location of dominating resistance as represented by the Blot number

with a wet bulb temperature of $45^{\circ} \mathrm{C}$. Assuming $\mathrm{Sh}_{\mathrm{c}}=2$, we get for the air side mass transfer coefficient $k_{g, \text { eff }}=0.2 \mathrm{~m} / \mathrm{s}$. From Fig.1 follows that $\rho_{w s}^{s}=0.07 \mathrm{~kg} / \mathrm{m}^{3}$, and from Fig. 3. a value of $D_{\text {eff }}$ of about $1 \times 10^{-10} \mathrm{~m}^{2} / \mathrm{s}$. At $45 \%$ solids we have roughly $\rho_{s}=500$ $\mathrm{kg} / \mathrm{m}^{3}$, and a typical value of $\mathrm{X}_{\mathrm{cr}}^{*}$ is about $0.4 \mathrm{~kg} / \mathrm{kg}$ ds. Thus follows for the Biot number $\mathrm{Bi}=70$. This means that diffusion limitation will be of great importance in this process. If we would have a granule with the same dimensions, which would be dried in a drum drier, the time-average mass transfer coefficient would be much smaller, say $k_{g, e f f}=1 \times 10^{-3} \mathrm{~m} / \mathrm{s}$, and the Bi-number would be equal to $\mathrm{Bi} \approx 0.35$, indicating that the main resistance would lie in the air phase.

The scale of observation : the concept of "grain size"

There is one rule which is very important in scale-up in general : "you can never scale-up all phenomena and effects in a similar way". Therefore it is important to decide what are the dominating features. A second rule, especially useful for drying is : "The relative importance of influences may and probably will change with scale". The latter statement takes into account that in full-scale operation one wants to make efficient use of energy and of equipment volume and thus configuration, air/product ratios and flow patterns may differ considerably from pilot or laboratory situation. Thus drying rate, air 


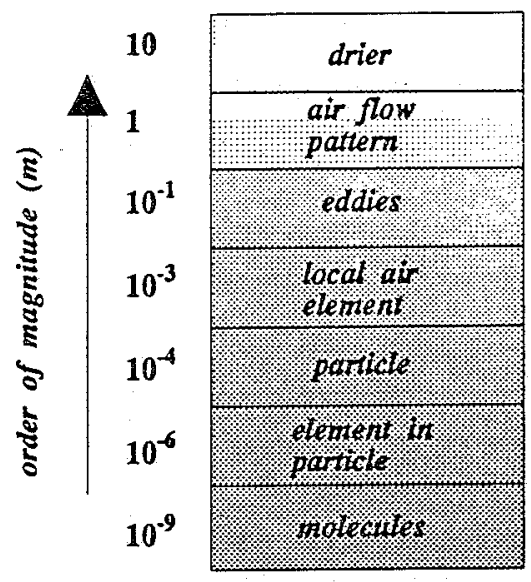

Fig.7. Different scales of observation for spray drying

temperature and humidity distribution, product particle size, flow and residence time (distribution) are in general scale-dependent; as a consequence also for many product quality aspects will hold the same.

Analogously to the considerations in mathematical physics we will have to look at drying processes on a number of levels of the scale of observation. In terms of modeling we have a multi-level, multi-distributed system. Our approach may have to vary between yery "coarse-grained" (whole equipment) and extremely "fine-grained" (element within a particle), as illustrated in Fig. 7. The critical size of observation, or "critical grain size" is determined by the level of the dominating effects, either on drying rate or on product quality. If we have easy estimating methods available, the determination of this critical scale is simplified. In the previous section we estimated for a droplet of carbohydrate solution in a spray drier a value of the Biot number of typically 70 . This means that in scaling up we will have to take diffusional limitations into account, and thus the critical grain size in this case is the droplet size. For systems in which Bi is very low, the critical grain size is that of a characteristic element of the drying air.

Of course the above is a bit simplified; one has to consider various aspects of the drying process, which may differ in the scale of importance. However the approach has the advantage that one is able to concentrate on sub-processes, without loosing track of the 
greater coherent process structure. In multi-disciplinary discussions about scale-up and product properties it may contribute enormously to the clarity if physical ideas are attached to the scale of consideration.

\section{PRODUCT PROPERTIES}

Generally speaking there is a host of product properties, of which a number are very product - specific, and others are somewhat more general. An attempt at a rough classification is the following :

piece properties : for discrete products like clay bricks, and gypsum boards very specific requirements are defined, like mechanical strength, absence of defects, and tolerances in dimensions.

intrinsic properties : these are properties in bulk products which are defined also for single particles or even small elements inside; examples are moisture content, aroma content, nutritional value, specific surface area for porous products.

extensive powder properties : some properties can only be related to many-particle systems, such as bulk density, flowability, wettability.

In general piece properties are very much dependent on the local drying history of elements of the dried units; unless we are drying at extremely low Biot numbers we will allways have differences between these histories in pilot or lab experiments and full-scale. Modelling including mechanical stresses and deformations may be required; the grain size is typically that of a small element within the drying material. Modelling is difficult and requires complex finite-element methods and the determination of constitutive properties. It may however lead to rules connecting local drying rates to occurrence of defects. Examples in this area are work on pasta by Andrieu et al. [3], and on clay by Ketelaars et al. in our laboratory [2]. The rules, combined with the increased insight, can be used in design of better lab experiments, and in analyzing local situations in full scale drying chambers.

Intrinsic properties are related to the average product properties by the following rules for averaging :

$$
Y_{\mathrm{ay}}=\int_{0}^{\infty}\langle\mathrm{Y}\rangle \mathrm{f}\left(\mathrm{d}_{\mathrm{p}}\right) \mathrm{d}\left(\mathrm{d}_{\mathrm{p}}\right)
$$


in which $\mathrm{f}\left(\mathrm{d}_{\mathrm{p}}\right)$ is the particle size frequency distribution on dry mass base. The quantity $\langle\mathrm{Y}\rangle$ is the average of the property over the particle :

$$
<\mathrm{Y}=\int_{\mathrm{m}_{\mathrm{S}}} \mathrm{Yd}\left(\mathrm{m}_{\mathrm{s}}\right)
$$

in which $Y$ is the local property defined on a dry mass base.

In lab or pilot experiments the local drying simation may differ from that in full scale, leading to different gradients inside a given particle with size $d_{p}$, leading to different $\left\langle Y>\right.$ for the same $d_{p}$. Moreover the particle size distribution will differ between scales, and thus also $Y_{\text {av }}$ will be affected. Modelling may provide insight into the magnitude of these effects, and also provide directives towards measurement in various situations. A famous question in practice is why two identical driers in identical situations give different products; analysis of particle size distributions reveals in most cases that situations are not identical at all. Also this analysis may directly relate the effect of the different distributions to the considered properties.

Extensive powder properties are very important since they have a large impact on product handling and performance. Unfortunately they are the most difficult to describe quantitatively. From physical considerations however at least qualitative relations may be laid to surface area, particle size distribution, contact angle, surface composition. From modelling differences in situations may be understood, giving a better handle to improve properties. In our own laboratory we recently studied the spray - drying of high-fat food products and could explain properties like bulk density and free-fat content by approximating models.

\section{OVERALL MASS AND ENTHALPY BALANCES}

In any type of consideration balances must be made over the whole dryer. For the case of air drying without additional energy input we may write the general balances over the black box depicted in Fig. 8. 


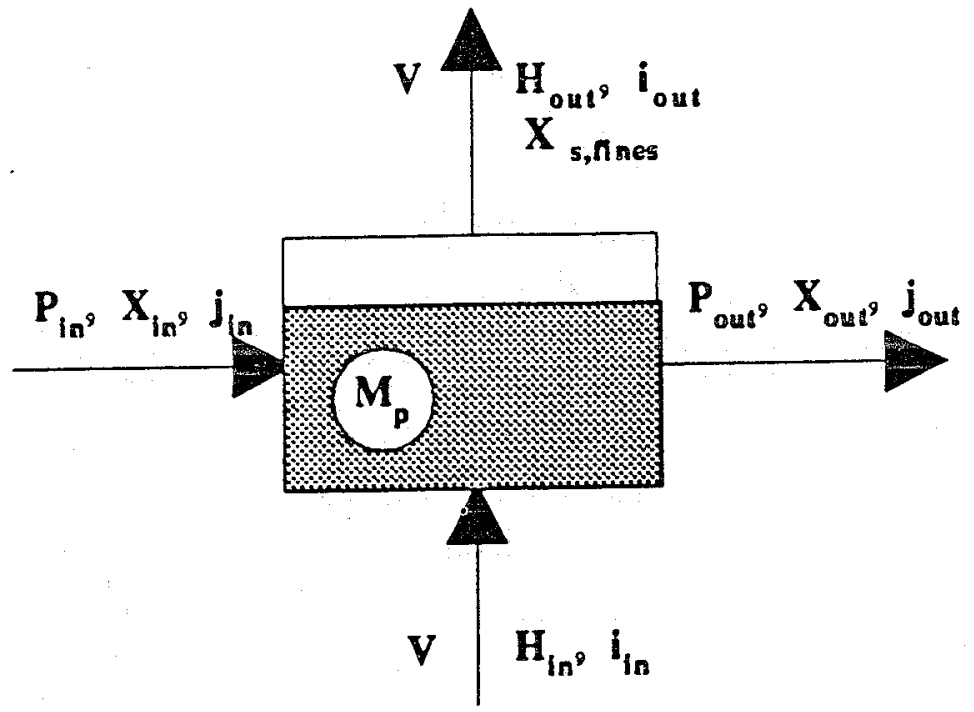

Fig.8. Black-box representation of drier

For solids we have :

$P_{\text {in }}-P_{\text {out }}=\frac{d M_{p}}{d t}+V \cdot X_{\text {s,fines }}$

in which $\mathrm{P}$ is the dry feed or product stream $[\mathrm{kg}$ solids $/ \mathrm{hr}], \mathrm{M}_{\mathrm{p}}$ is the dry solids hold-up inside the drier $[\mathrm{kg}], \mathrm{V}$ is the dry air stream $[\mathrm{kg}$ dry air $/ \mathrm{hr}]$, and $\mathrm{X}_{\mathrm{s} \text {,fines }}$ is the fines load on dry basis in the outlet air.

For the moisture the balance reads :

$P_{\text {in }} X_{\text {in }}-P_{\text {out }} X_{\text {out }}=\frac{d\left(M_{p} X_{a v}\right)}{d t}+V\left(H_{\text {out }}-H_{\text {in }}\right)+V X_{s, \text { fines }} X_{w, f i n e s}$

For the enthalpy the balance reads :

$P_{\text {in }} j_{\text {in }}-P_{\text {out }} j_{\text {out }}=\frac{d\left(M_{p} j_{\text {av }}\right)}{d t}+V\left(j_{\text {out }}-j_{\text {in }}\right)+V x_{\text {s,fines }} j_{\text {fines }}+\frac{d\left(J_{\text {equip }}\right)}{d t}+$ loss 
In this $j$ is the enthalpy of the drying material, defined on dry solids base, and $J$ equip is the heat content of the equipment.

The enthalpy $\mathrm{j}$ can be expressed as :

$\mathrm{j}=c_{\mathrm{ps}}+\dot{X}_{\mathrm{w}} c_{\mathrm{pw}}$

For the case of continuous steady state drying, neglecting fines carry-over and heat losses, we have $\mathrm{P}_{\text {in }}=\mathrm{P}_{\text {out }}=\mathrm{P}$ and obtain :

$P\left(X_{\text {in }}-X_{\text {out }}\right)=V\left(H_{\text {out }} \cdot H_{\text {in }}\right)$

$P\left(j_{\text {in }}-j_{\text {out }}\right)=V\left(j_{\text {out }}-j_{\text {in }}\right)$

For the case of a fed - batch drier, again neglecting heat and fines losses, we have :

$$
\frac{d M_{p}}{d t}=P_{\text {in }}
$$

$\frac{d\left(M_{p} X_{a v}\right)}{d t}=P_{\text {in }} x_{\text {in }}-V\left(j_{\text {out }}-j_{\text {in }}\right)$

$\frac{d\left(M_{p} j_{a v}\right)}{d t}=P_{\text {in }} j_{\text {in }}-V\left(j_{\text {out }}-j_{\text {in }}\right)-\frac{d\left(J_{\text {equip }}\right)}{d t}$

The last term should in general be considered, especially in control models. However for many approximate studies we may neglect it. For a batch drier the above is easily simplified by putting $P_{\text {in }}=0$, and $M_{p}$ constant.

\section{DISTRIBUTED MODELS FOR MASS TRANSFER AND DEGRADATION}

The difrusion equation for water

It has been well established that in drying of many materials during a large part of the process the drying rate is determined by diffusional resistance inside the drying material. The transport mechanism may be molecular diffusion in an amorphous material, 
such as in spray drying coffee extract, or a more complex simultaneous transport in small pores in a solid matrix as in the drying of structured materials such as clay. However also in the latter case one may with success also lump various phenomena into a model with an effective diffusion coefficient. In general the diffusion equation for such a system reads :

$$
\frac{\partial \rho_{w}}{\partial t}=-\nabla \cdot\left(n_{w}\right)
$$

with :

$$
\mathrm{n}_{\mathrm{w}}=-D_{\mathrm{w}} \nabla \rho_{\mathrm{w}}+\mathrm{v}^{\mathrm{a}} \rho_{\mathrm{w}}
$$

in which $\rho_{w}$ is the water concentration $\left[\mathrm{kg} / \mathrm{m}^{3}\right], a_{w}$ is the water flux with respect to $a$ coordinate fixed to the drying specimen $\left[\mathrm{kg} / \mathrm{m}^{2} \mathrm{~s}\right], D_{w}$ is the (effective) mutual diffusion coefficient of water and solids $\left[\mathrm{m}^{2} / \mathrm{s}\right]$ and $v^{\mathrm{a}}$ is the volume-averaged velocity with respect to the chosen coordinate $[\mathrm{m} / \mathrm{s}]$.

Often one can simplify the transport model to a simple geometry : an infinitely extended slab, drying from one side, an infinite cylinder or a (hollow) sphere. If then the coordinate is fixed with respect to the non-drying side of the slab or the centre of the cylinder or sphere respectively we obtain :

$$
\frac{\partial \rho_{\mathbf{w}}}{\partial t}=\frac{1}{r^{v}} \frac{\partial}{\partial r}\left(\mathbf{r}^{v}\left\{D_{w} \frac{\partial \rho_{w}}{\partial r}-v^{a} \rho_{w}\right\}\right)
$$

in which $v$ is a geometry factor : $v=0$ for the slab, $v=1$ for the cylinder, $v=2$ for the sphere. If the system does not expand or shrink the volume-averaged velocity is equal to 0 ; this is also the case for systems with a shrinking boundary but without internal volume production or contraction (a slab in which the total shrinkage exactly balances the volume of water removed, or an isotropically drying totally filled sphere). In the case of an inflating droplet the velocity can be expressed in terms of the growth of the internal gas bubble :

$$
v^{\square} r^{2}=\frac{d R_{g}^{3}}{d t}
$$

in which $R_{g}$ is the radius of the gas bubble. 
In order to complete the set we need the initial and boundary conditions. In general we have for the initial condition :

$$
t=0 \quad R_{\text {in }, 0} \leq r \leq R_{\text {out }, 0} \quad \rho_{w}=\rho_{w, 0}
$$

in which $R_{\text {in, } 0}$ is the coordinate of the inner surface (which of course equals 0 for slabs, massive cylinders and solid spheres). In case $R_{\text {in }}=0$ we have in general the no - flux condition as one of the boundary conditions :

$$
t>0 \quad r=0 \quad \frac{\partial p_{w}}{\partial r}=0
$$

and for an inflating bubble approximately :

$$
t>0 \quad r=0 \quad n_{w, b}=0
$$

in which $n_{w, b}$ is the water flux with respect to the bubble-liquid interface.

At the external interface we have the equality between the internal and the external water flux through the phase boundary :

$$
j_{w, i}=-D_{w} \nabla \rho_{w}+\left(v^{\square}-v^{i}\right) \rho_{w}=k_{e f f}\left(\rho_{w, i}^{\prime}-\rho_{w, b}^{\prime}\right)
$$

in which $k_{\text {eff }}$ is the effective mass transfer coefficient in the gas phase $[\mathrm{m} / \mathrm{s}]$, and $\rho_{w_{j}}^{\prime}$ and $\rho_{w, b}^{\prime}$ are the water concentrations in the drying air at the interface and in the bulk respectively. The velocity of the interface is indicated by $v$, while $j_{w, i}$ stands for the flux of water with respect to the moving interface $\left[\mathrm{kg} / \mathrm{m}^{2} \mathrm{~s}\right]$.

At the interface we assume equilibrium between the two phases:

$$
\rho_{\mathrm{w}, \mathrm{i}}^{\prime}=\mathrm{A}_{\mathrm{w}, \mathrm{i}} \rho_{\mathrm{w}, \mathrm{sat}}^{\prime}=\mathrm{A}_{\mathrm{w}, \mathrm{i}} \frac{\mathrm{P}_{\mathrm{w}, \mathrm{s}} \mathrm{M}_{\mathrm{w}}}{R \mathrm{~T}}
$$

in which $P_{w, S}$ is the saturation water vapour pressure $[\mathrm{Pa}], P_{\mathrm{w}, \text { sat }}^{\prime}$ the corresponding water vapour concentration $\left[\mathrm{kg} / \mathrm{m}^{3}\right], M_{\mathrm{w}}$ the molecular mass of water $[\mathrm{kg} / \mathrm{kmole}], R$ the gas constant [J/kmole $\mathrm{K}]$, $\mathrm{T}$ the particle absolute temperature[K].

The water activity $A_{w, i}$ depends on the interfacial water concentration in the drying material and the temperature as described by the water vapour sorption isotherm : 


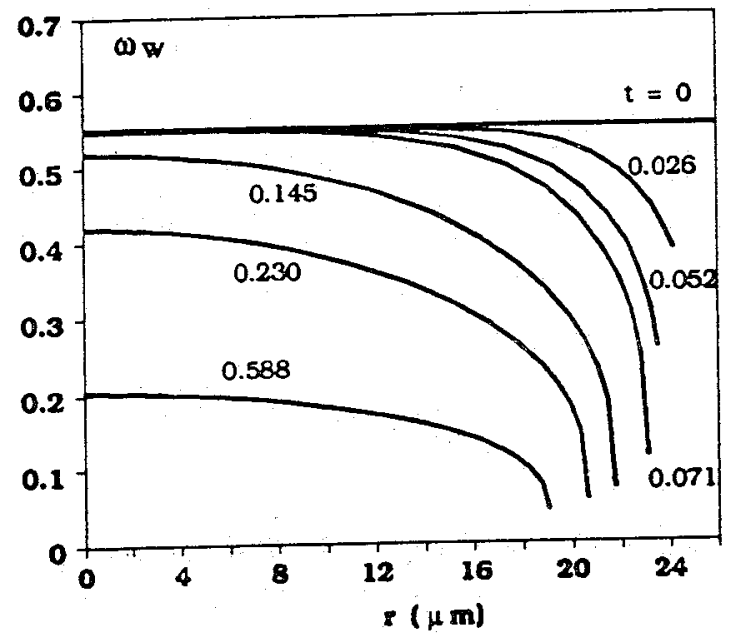

Fig. Water concentration profiles inside a droplet of skim milk during spray drying

$$
A_{w, i}=A_{w}\left(p_{w, i}, T\right)
$$

In many practical situations the limitation for heat transfer lies in the drying air, leading to a virtually uniform temperature profile inside the drying material. We may then write an overall heat balance :

$$
\alpha_{\text {eff }}\left(T_{b}-T\right) S=\frac{d}{d t}\left[m_{s} j+m_{g} i\right]+j_{w, i} i v
$$

in which $\alpha_{\text {eff }}$ is the effective heat transfer coefficient $\left[W / m^{2} K\right], T_{b}$ is the bulk temperature of the air $[\mathrm{K}], \mathrm{S}$ is the surface area $\left[\mathrm{m}^{2}\right], \mathrm{m}_{\mathrm{s}}$ is the solids mass, and $\mathrm{m}$ is the included dry gas mass, and $\mathrm{j}$ and $\mathrm{i}$ stand for the enthalpies of the drying material per $\mathrm{kg}$ of dry solids, and $\mathrm{i}_{\mathrm{v}}$ stands for the enthalpy of water vapour $[\mathrm{J} / \mathrm{kg}]$.

The solution of the above equations has been subject of considerable work in the seventies [4-9]. In order to cope with the problems of moving boundaries coordinate transformations to solids-based coordinates were derived, leading to non-shrinking coordinates. Due to the concentration-dependence of the diffusion coefficient standard 
numerical methods failed, and special numerical methods had to be developed. Systems studied in this way were the drying of slabs of maltadextrin solutions [4,5], of glucose solutions [6], of droplets of aqueous maltose solutions [7,8], and the drying of skim milk [9]. In Fig. 9 an example is given of the water concentration profile inside a solid droplet during spray drying.

\section{Loss of volatile aroma components}

Also this aspect has been subject of considerable study, both experimentally and theoretically. A recent overview is given by Coumans et al. [10]. The basic considerations for modelling are the simplification to a ternary system, consisting of water, dissolved solids and a trace aroma component. The aroma component is thought to be very volatile and not thermally degradable within the region of interest. Analogously to the water balance the diffusion equation for such an aroma component reads :

$$
\frac{\partial \rho_{a}}{\partial t}=-\nabla \cdot\left(n_{a}\right)
$$

In the flux equation for aroma however now both the effect of a gradient in aroma concentration and that in the water or solids concentration should be taken into account :

$$
\mathrm{n}_{\mathrm{a}}=-D_{\mathrm{aa}} \nabla \rho_{\mathrm{a}}-D_{\mathrm{aw}} \nabla \rho_{\mathrm{w}}+\mathrm{v}^{\mathrm{a}} \rho_{\mathrm{a}}
$$

Both the straight aroma diffusion coefficient $D_{\text {aa }}$ and the cross-diffusion coefficient $D_{\text {aw }}$ are strongly dependent on the water concentration. At low water concentrations the diffusion coefficients become much lower than that of water, in a drying process thereby effectively a semi-permeable dry skin is formed through which aroma transport is virtualiy zero.

At the interface with the drying air because of the high volatility can be written :

$$
t>0 \quad r=R \quad \rho_{a}=0
$$

The solution of the aroma diffusion equation can only be done simultaneously with that for the water diffusion. In a number of papers a detailed account is given of the results $[6,8]$. Systems considered until now have been layers and solid spheres. What was stated 
for the solution of the water diffusion equation also holds for that of aroma : special numerical techniques had to be designed, and experimental data are very scarce.

Thermal degradation of heat-labile compounds

In a number of studies the thermal degradation of heat-labile components was investigated. For a large class of problems the degradation may be treated as first order reaction :

$$
\frac{d \rho_{i}}{d t}=-k_{r} \rho_{i}
$$

in which the degradation rate constant depends on the water concentration and temperature, for a given composition of the solids. For a number of heat-labile enzymes was found that the rate constant decreased sharply with decreasing water concentration and increased with temperature. This has been included in spray drying models [8,9]. A typical example could look like Fig. 10, as is used in modelling studies in courses by us. Also in a study of short-cut methods based on the power-law diffusion, Liou found short-cut methods to determine water concentration profiles inside the drying material, and integrated enzyme inactivation in his calculations. In the basic modelling it is assumed that the component, say enzyme, is immobile with respect to the dissolved solids phase. The diffusion equation is solved, and simultaneously the enzyme profile within the particle is calculated. This profile is then integrated over the particle to obtain the average rest activity.

In recent studies it has been shown that generally for such components as enzymes the above kinetics seem to hold $[19,20]$. However in the drying of micro-organisms such as yeasts or lactic acid bacteria a much larger degradation occurs than would be expected on the grounds of the separate inactivation kinetics integrated with the drying curve [12].

\section{Regular Regimes and short-cut calculation methods}

In his excellent thesis Schoeber developed a framework for short-cut calculation methods for desorption processes with concentration-dependent diffusion coefficients [13]. 


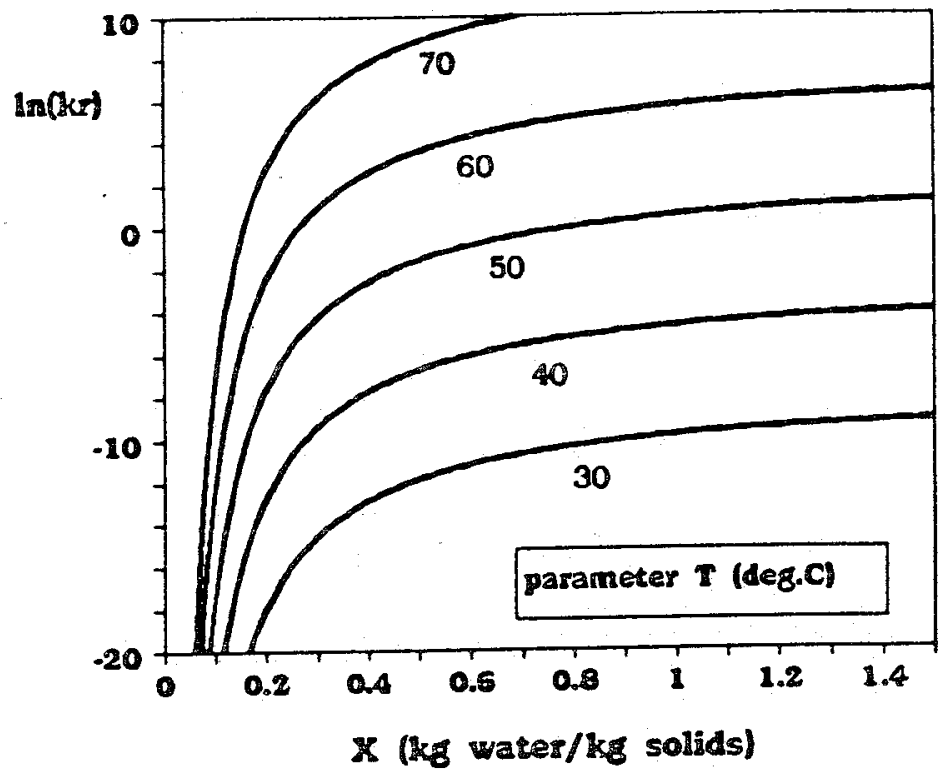

Fig.10. Typical dependence of degradation rate constant on water concentration and temperature

This was based on the Regular Regime observation : For a given set of boundary conditions the drying rate will after some time only depend on the actual moisture content, and the influence of the initial condition decreases to virtually zero. To describe a drying process he identified three stages : the Constant Activity Period, the Penetration Period, and the Regular Regime, and methods to calculate transition points between these regions. Furthermore he derived relationships between the concentration dependence of the diffusion coefficient and the Regular Regime part of the drying curve, thereby opening the way of determination of the diffusion coefficient from relatively simple drying experiments:- The advantage of his methods was the generality of the treatment, which held for all kinds of concentration dependencies.

In further studies Liou and Coumans developed methods of also calculating the concentration profiles inside the material by short-cut methods, for the special case of a concentration dependence given by the power-law relation of the type $\mathrm{D}=\mathrm{D}_{0} \mathrm{X}_{\mathrm{w}}^{\mathrm{a}}$. Also they provided several simplified calculation methods for various geometries [11,12]. 


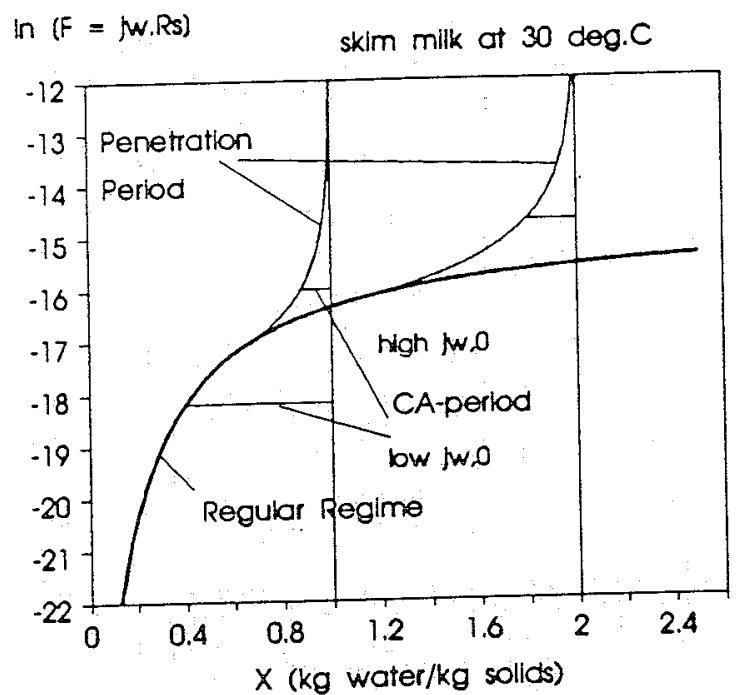

Fig.11. Drying curves for a layer of skim milk at 30 degs. $C$, at different initial water concentrations and fluxes, illustrating various drying regimes

In various treatments different definitions have been used of intermediate parameters, in the form of dimensionless groups. Here we have stripped the treatment to "bare-bone" variables; a certain loss of generality is thereby compensated by a more compact discussion.

\section{Drying curves and Regular Regimes}

As has been presented by Schoeber and others $[13,14,15]$, a very convenient way of presenting a drying curve is that by ploting the fux parameter $F$ vs. the average moisture content $X$ on solids base.

The flux parameter is defined here as :

$$
F=j_{w} R_{s}
$$


in which $j_{w}$ is the water flux $\left[\mathrm{kg} / \mathrm{m}^{2} \mathrm{~s}\right]$ and $R_{S}$ is the solid thickness or solid radius [m]. For a slab $R_{s}$ is the thickness to be reached upon total shrinkage after complete drying; for a solid sphere it would be the final radius, while for a hollow sphere it would be the thickness of the solid part of the shell at a given bubble size.

Both from experimental data and from numerical calculations follows that three regimes may be distinguished, as illustrated in Fig. 11. Starting with a given initial moisture content we first have a period in which the interfacial concentration is so high that the water activity at the interface remains virually constant : the Constant Activity Period. For a slab the flux parameter remains constant since the flux is determined by the external conditions for a given slab temperature. Inside the layer concentration profiles build up, and thus at a certain point the interfacial water concentration decreases below the point of inflection of the sorption isotherm, and so the flux will also start to decrease. Since the diffusion coefficient in that region is strongly decreasing with decreasing water concentration, the interfacial water concentration will rapidly drop to a value close to equilibrium with the drying air. If the initial flux was high, the water concentration at the non-evaporating side of the slab will still have the initial value; in that case the profiles will start to penetrate, until the heart is reached. We than have a Penetration Period. Once the center concentration starts to decrease we go over into the third period, the Regular Regime. The interesting observation made by Schoeber is that independent of initial conditions all drying curves, for the given layer temperature and air humidity, merge into the same Regular Regime curve. Also starting from a given moisture content at high F-values, the penetration parts of the drying curves merge into the same Penetration Period curves. When the initial flux, or rather $F$, is low, during the $C A$-period the concentration profiles will be shallow, and there is no Penetration Period, but the CA-period goes over directly into the Regular Regime.

Summarizing in the same terms as used by Schoeber we may state that :

- The Regular Regime curve is the "grandparent curve" for a given material, from which all drying curves may be derived; it does not depend on initial moisture content or initial flux:

- The Penetration Period is the "parent curve" for drying curves for a given initial moisture content at high initial F-values; the curve however does not depend on initial flux itself..

- The Constant Activity Period is determined by external conditions and initial moisture content, and thus is a kind of "child curve". 
Some first rules for drying calculations with the RR-method

The basic ideas in the previous section must be refined for a full treatment. First of all the RR-curve depends on geometry; we will come back to that later. Further the RR-curve for a given geometry depends on the equilibrium value $\mathrm{X}_{\mathrm{i}}$ of the interfacial concentration. Formally written it was found that:

$$
F_{R R}(T, X, X)=F_{R R}(T, X, 0)-F_{R R}(T, X, 0)=F_{R R}^{*}(T, X)-F_{R R}^{*}\left(T, X_{i}\right)
$$

in which $F_{R R}^{*}(T, X)$ is the Regular Regime curve for interfacial concentration $X_{i}=0$, for a given geometry.

Thus the $R^{*}$ curve for a slab may be regarded as a material property. The dependence on the temperature is described by means of an Arrhenius equation :

$$
F_{R R}^{*}(T, X)=F_{R R}^{0}(X) \exp \left\{-E_{F}(X) / R T\right\}
$$

in which the frequency factor $F_{R R}^{0}(X)$ and the activation energy $E_{F}(X)$ both depend on the average moisture content.

For the description of a drying curve at constant layer temperanure we need to know the transition points. The first one is given by the transition between PP and RR, for which the criterion is :

$$
d\left(\ln F_{R R}\right) / d X=1 /\left(X_{0}-X\right)
$$

which can be determined numerically, thus giving the transition value $\mathrm{X}_{\mathrm{T}}$, from which also the value of the flux parameter $F_{T}$ follows. From basic considerations now follows that for the Penetration Period holds :

$$
F_{P P}=\left(E_{T} F_{T}\right) / E
$$

in which $E=\left(X_{0}-X\right) /\left(X_{0}-X_{i}\right)$, with $X_{i}$ the interfacial moisture content. For the constant activity period the flux $\mathrm{j}_{\mathrm{W}}$ follows from extemal conditions, as given by Eqs.(4-7) and (4-8), with $A_{W}=1$. Intersection of the corresponding F-value with either the PP-curve or the RR-curve gives then the transition of $C A$ to the other periods, and thus the whole drying curve is known. 
For a layer the value of $R_{s}$ is equal to :

$$
\mathrm{R}_{\mathrm{s}}=\mathrm{L}_{0} \rho_{\mathrm{s}, 0} / \mathrm{d}_{\mathrm{s}}=\mathrm{L}_{0} /\left(1+\mathrm{X}_{0} \mathrm{~d}_{\mathrm{s}} / \mathrm{d}_{\mathrm{w}}\right)
$$

in which $\rho_{s, 0}$ is the initial solids concentration in $\left[\mathrm{kg} / \mathrm{m}^{3}\right]$, and $d_{s}$ and $d_{w}$ are the specific densities of water and dissolved solids respectively $\left[\mathrm{kg} / \mathrm{m}^{3}\right]$.

The drying time is given by :

$$
t=\operatorname{ds}_{s}{ }_{s}^{2} \int_{X}^{X_{0}} \frac{d X}{F}
$$

\section{Short-cut estimation of aroma losses}

Some 15 years ago we designed a short-cut estimation method for the loss of aroma by diffusion [16,17]. In practical spray drying also losses occur upon atomisation; with the aid of the correlation method also an estimate was made of those. Both from experiments and numerical results of the diffusion equations it appeared that in good approximation diffusional aroma loss mainly takes place during the constant activity period. Therefore a correlation method was set up in which the aroma loss is described by an effective Fourier number :

$$
\mathrm{Fo}_{\mathrm{a}}=\mathrm{D}_{\mathrm{a}, \text { eff }} \varphi_{\mathrm{c}}=\mathrm{D}_{\mathrm{a}, \text { eff }} \mathrm{t}_{\mathrm{c}} / \mathrm{R}_{0}^{2}
$$

Herein $D_{a, e f f}$ is an effective aroma diffusion coefficient, $t_{c}$ is the length of the CA-period, and $R_{0}$ is the initial thickness of a one sided drying slab or radius of a droplet. The relation between the fractional aroma retention and the Fourier number may be approximated by :

$$
\begin{aligned}
& A R=\sum_{n=0}^{\infty} A_{n} \exp \left[-\beta_{n}^{2} F o_{a}\right] \\
& A_{n}=\frac{8}{\pi^{2}} \frac{1}{(2 n+1)^{2}} \quad \beta_{n}=2 / A_{n} \quad \text { slab }
\end{aligned}
$$




$$
A_{n}=\frac{6}{\pi^{2}} \frac{1}{n^{2}} \quad \beta_{n}=6 / A_{n} \quad \text { solid sphere }
$$

or by the well-known short-time and long-time approximations :

$$
\left.\begin{array}{ll}
\mathrm{AR}=1-2\left(\mathrm{Fo}_{\mathrm{a}} / \pi\right)^{1 / 2} & \mathrm{Fo}_{\mathrm{a}}<0.2 \\
\mathrm{AR}=\frac{8}{\pi^{2}} \exp \left[-\pi^{2} \mathrm{Fo}_{\mathrm{a}} / 4\right) & \mathrm{Fo}_{\mathrm{a}}>0.2
\end{array}\right\} \text { slab } \quad(5-10 \mathrm{a})
$$

The length of the CA-period was correlated to the initial flux and other parameters by means of the following :

$$
\begin{array}{ll}
\varphi_{c}=\frac{B}{\varepsilon} & \text { slow drying } \\
\varphi_{c}=\frac{F_{W}}{\varepsilon} & \text { fast drying }
\end{array}
$$

Herein $\varepsilon$ is a somewhat different kind of flux parameter :

$$
\varepsilon=j_{w 0} R_{0} / d_{w}
$$

with $j_{w 0}$ the initial water flux. The value of $B$ can be derived for totally flat water concentration profiles :

$$
\begin{array}{ll}
B=\frac{\left(X_{0}-X_{c}\right) d_{s} / d_{w}}{\left(1+X_{0} d_{s} / d_{w}\right)} & \text { slab } \\
B=\frac{1}{2}\left[1-\left[\frac{1+X_{c} d_{s} / d_{w}}{1+X_{0} d_{s} / d_{w}}\right]^{2 / 3}\right] & \text { solid sphere }
\end{array}
$$

Herein $X_{0}$ is again the initial water content on dry base, and $x_{c}$ is the critical interfacial moisture content; for $\mathrm{X}_{\mathrm{c}}$ the value may be taken at which according to the sorption isotherm $A_{w}=0.90$. While for this regime of extremely slow drying only $X_{c}$ appears as material property, for the case of fast drying the diffusion properties enter, 
as dependent on initial moisture content and sample temperature. This could be well correlated by :

$$
F_{w}=F_{w}^{0} \exp \left[-\frac{E_{w}}{R T}+f_{w w} \rho_{w 0} / d_{w}\right]
$$

For aqueous maltodextrin solutions the following values were found :

$$
\mathrm{X}_{\mathrm{c}}=0.429 \quad \mathrm{~F}_{\mathrm{w}}^{0}=1.35 .10^{-9} \mathrm{~m}^{2} / \mathrm{s} \quad \mathrm{E}_{\mathrm{w}} / \mathrm{R}=2764 \mathrm{~K}^{-1} \quad \mathrm{f}_{\mathrm{w} w}=8.781
$$

The question whether to consider a specific situation as slow of fast drying is easily solved by calculating both values of $\varphi_{c}$ according to Eq. (5-11) : the lowest value of $\varphi_{c}$ should be taken.

The effective aroma diffusion coefficient may be correlated by :

$$
D_{a, e f f}=D_{a}^{0} \exp \left[-\frac{E_{a}}{R T}+f_{a w} \rho_{w 0} / d_{w}\right]
$$

In Fig. 12 a plot is given of $\mathrm{D}_{\mathrm{a}, \text { eff }}$ vs. the solids concentration for the three components for a temperature of $50{ }^{\circ} \mathrm{C}$; as could be expected the effective diffusion coefficient decreases with increasing solids concentration and with increasing molecular mass of the aroma component.

In recent years more accurate methods have been developed to predict $t_{c}[15]$; also the loss of aroma has again been subject of more accurate measurement, as presented by by Coumans et al [10]. Thus in future a further refinement of this correlation method may be made. Still needed, but within reach, is the correlation for hollow spherical particles.

One of the interesting aspects of this short-cut method is that the basic data can again be determined from simple lab experiments in which layers of the material are dried. Thus the tedious determination by differential measurements, as well as the numerical computations, can be avoided.

\section{thermal degradation}

Again the use of short-cut methods would be welcome. As suggested in 1977, one very simple approximation would be to approximate the degradation rate by that for the average 


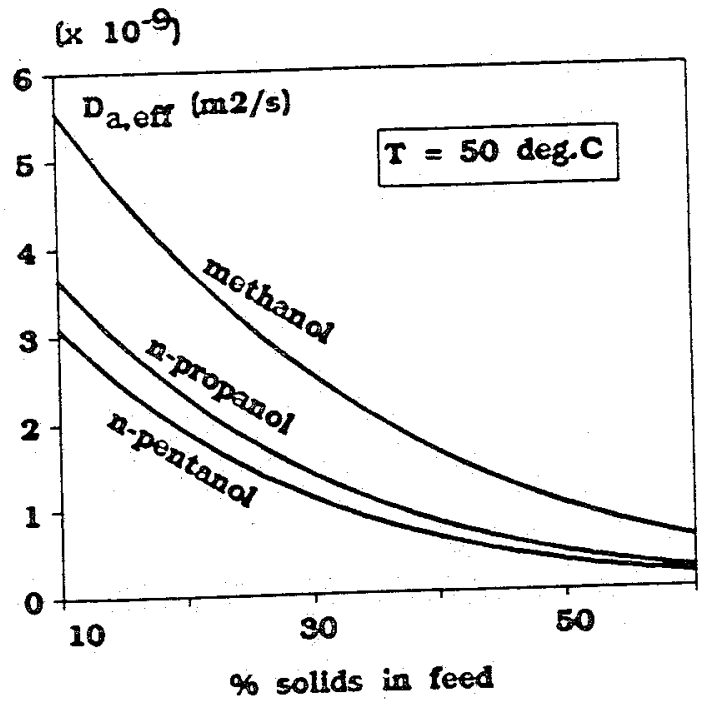

Fig.12. Elfectivo aroma diffusion coefficients for $n$ - atconols in aqueous maltodextrin solutions

moisture content, which is readily available from short-cut calculations [18]. Although this will give some deviations it will still be a handy tool in the predictions of trends.

\section{SPRAY DRYING OF LIQUID FOODS}

Approximation for spray drying of hollow particles

For spray drying we have in the majority of processes hollow spherical particles. From simulations it followed that for thin shells we can succesfully approximate the drying curve by that of a drying layer, provided that we use the following definitions :

$$
R_{s}=\left(R_{\text {out }}-R_{\text {in }}\right) /\left(1+X d_{s} / d_{w}\right)
$$

As of course the temperature of a drying particle is variable we will see a change in the inner and outer radius. For foods a good approximation is to assume a zero pressure 
difference between inside and outside. Thus follows at any time :

$$
\left(P_{w}+P_{\text {air }}\right)_{\text {in }}=P_{\text {tot }}
$$

with $P_{w, \text { in }} \approx A_{w}(X) \cdot P_{W, S}$

The inner radius at any time is then given by the conservation of included air :

$$
\mathrm{R}_{\mathrm{in}}^{3} \mathrm{p}_{\mathrm{air}}=\left(\mathrm{R}_{\mathrm{in}}^{3} \mathrm{p}_{\mathrm{air}}\right)_{0}
$$

Now during the CA-period the temperature remains constant, at wet-bulb temperature, and consequently the inner radius remains constant. Due to water loss the outer surface shrinks, and thus $R_{s}$ will also change. Since for the gas-phase Sherwood-number approximately holds :

$$
\mathrm{Sh}_{\mathrm{c}}=2
$$

the mass transfer coefficient in the gas phase varies roughly proportional to the outer radius :

$$
\mathrm{k}_{\mathrm{g}} \approx \mathrm{D}_{\mathrm{wg}} / \mathrm{R}_{\text {out }}
$$

and for not too high evaporation rates :

$$
\mathbf{k}_{\mathrm{eff}} \approx \mathbf{k}_{\mathrm{g}}
$$

Thus the flux for the CA-period follows from Eq.(4-7), and $R_{s}$ is calculated according to the above.

For the variable temperature it has been demonstrated by the mentioned authors that the RR-curves and PP-curves may be found by stepping over between the curves for constant temperatures. Thus we may divide the process into the following steps:

1 Find the wet-bulb temperature. Determine numerically the intersection point between either the $P P$ or the $R R$ and the CA-curve at this temperature. Find $F=F_{c a}(X)$ by calculation of $R_{S}$ and $j_{w}$ over a number of intervals.

2 Below the average critical moisture content take a small step in $X$. Calculate a piece of the drying curve in the prevailing regime, $P P$ or $R R$, at the interfacial water concentration corresponding to the temperature. Apply the mass and enthalpy balances : 


$$
\begin{aligned}
& \frac{d m_{w}}{d t}=\frac{d}{d t}\left(m_{s} X+m_{g} X\right)=-j_{w, i} s=-F S / R_{s} \\
& \frac{d J}{d t}=\frac{d}{d t}\left(m_{s} j+m_{g} i\right]=\left(F_{H}-F\right) s h_{v} / R_{s} \\
& F_{H}=\alpha_{e f f}\left(T_{b}-T\right) R_{s} / \Delta h_{v}
\end{aligned}
$$

in which $X^{\prime}$ is the absolute humidity inside the gas bubble, $\Delta h_{y}$ is the heat of evaporation, and $S$ is again the outer surface area. $J$ stands for the total enthalpy content.

From these balances follow the changes in moisture content $X$ of the shell and in temperature :

$$
\begin{aligned}
& \frac{d m_{w}}{d t}=\left[\frac{d X_{w}}{d t}\right]\left[\frac{\partial m_{w}}{\partial X_{w}}\right]_{T}+\left[\frac{d T}{d t}\right]\left[\frac{\partial m_{w}}{\partial T}\right]_{X_{w}} \\
& \frac{d J}{d t}=\left[\frac{d X_{w}}{d t}\right]\left[\frac{\partial J}{\partial X_{w}}\right]_{T}+\left[\frac{d T}{d t}\right]\left[\frac{\partial J}{\partial T}\right]_{X_{w}}
\end{aligned}
$$

The partial derivatives follow from numerical differentiation of relations for $\mathrm{m}_{\mathrm{w}}$ and $J$, and so the changes in $X$ and $T$ can be solved.

Thus a table of values of $F, R_{s}$ and $R_{\text {out }}$ can be made up over the whole concentration range in $X$. The drying time is then found by integration :

$$
t=\frac{m_{s}}{4 \pi} \int_{X}^{X_{0}} \frac{R_{s} d X}{F R_{o u t}^{2}}
$$

aroma retention

In Fig. 13 the aroma retention for the three alcohols has been plotted according to the correlation method for a typical situation in our pilot spray drier, as reported by 


\section{AR}

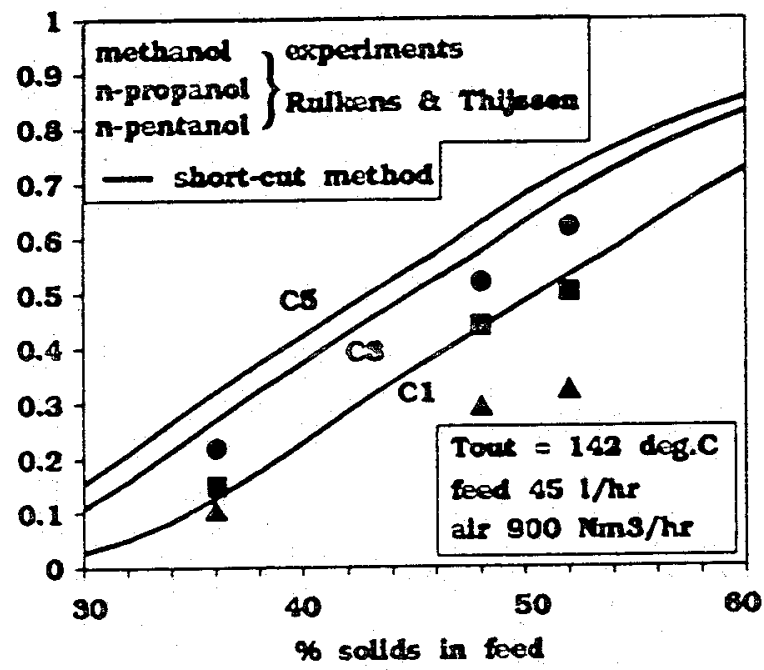

Fig.13. Predicted aroma retention in spray drying model aroma components compared with experiments

Rulkens and Thijssen [19]. From the mass balance over the drier the air humidity was calculated for the range in feed concentrations, and with the above the aroma retention was estimated for solid spheres. As can be seen the experimental data are roughly at $70 \%$ of the predicted ones with this method. This may partly be due to losses on atomization, partly because in reality the particles were not solid but hollow, which probably would lead to lower theoretical retentions as well. We see however that the trends found experimentally are reflected also in the predictions. The increase in retention with increasing solids concentration is caused by the lower aroma diffusion coefficient and the shorter length of the CA-period, as indicated in Fig. 14.

\section{thermal degradation}

This is illustrated in Fig. 15, in which we calculated the drying history of skim milk hollow particles in air of $70{ }^{\circ} \mathrm{C}$ and a humidity of $0.0518 \mathrm{~kg} / \mathrm{kg}$, with an initial gas volume of $20 \%$. Simultaneously we integrated the reaction rate at the average 
$\times 10^{6}\left(\mathrm{~s} / \mathrm{m}^{2}\right)$

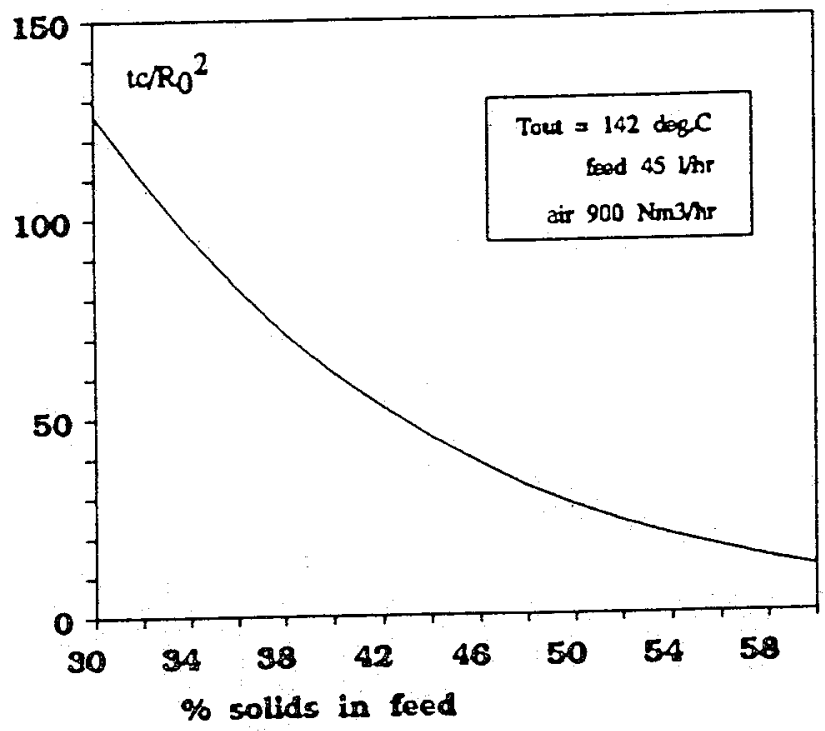

Fig.14. Reduced length of constantrate period in spray drying of aqueous maltodextrin solutions

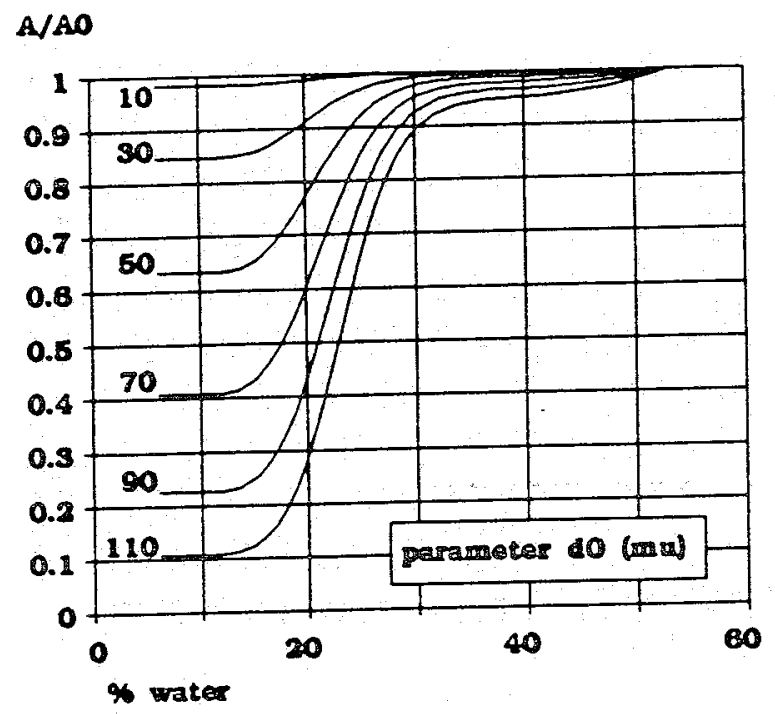

Fig 15. Rest activity after spray drying skim-milk particles, calculated with a model degradation reaction (fig. 10) on the basis of the average water content 
concentration and prevailing particle temperature. We see a very large influence of the initial droplet diameter on the estimated final rest activity, which is caused by the longer drying and thus reaction times for such particles, the times being proportional to a power of $R_{0}$ between 1 and 2, depending on the Biot number. This effect is also found in more detailed calculations.

\section{Simple approximation of particle motion in spray drying}

Although at present considerable effort is taken to model the motion of both particles and air in spray driers by means of Computational Fluid Dynamics, this has as yet not led to user-friendly applications. For the purpose of estimation a relatively simple approximation is found in the single-particle motion [8]. This model lends itself well for both uniform air flow and for swirling motion, and since it is of the same kind of numerical complexity as the short-cut methods for drying particles it can easily be integrated with those.

For the equation of motion we may write :

$$
m \frac{d u}{d t}=\left(m-m^{\prime}\right) g-C_{w} A_{c s} 1 / 2 p_{1} w|w|
$$

Herein $m$ is the particle mass, $m^{\prime}$ the mass of displaced air, $u$ the velocity vector of the particle with respect to stationary coordinates, $g$ the gravity acceleration vector, $C_{w}$ the drag coefficient $A_{c s}$ the cross-sectional area and $\rho_{1}$ the density of air. The relative velocity of the particle with respect to that of the air $\mathbf{v}$ is denoted by $w=u-v$.

The drag coefficient $C_{w}$ depends on the Reynolds number; a continuous calculation can be made by means of the correlation of Kaskas [20] :

$$
R e \leq 2.10^{5} \quad C_{w}=\frac{24}{R e}+\frac{4}{R e^{0.5}}+0.40
$$

in which $R e=p_{1}|w| d / \mu_{1}$.

The absolute value of the velocity difference vector, $|w|$, is given by :

$$
|w|=\left[w_{x}^{2}+w_{y}^{2}+w_{z}^{2}\right]^{1 / 2}
$$




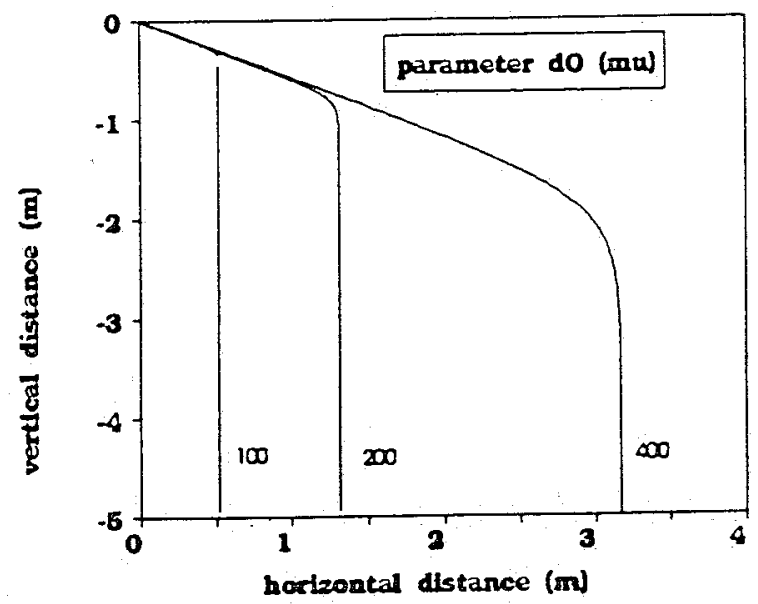

Fig.16. Horizontal and vertical trajectories calculated as single particle behaviour, initial velocity $200 \mathrm{~m} / \mathrm{s}$ at $60 \mathrm{deg}$ angle with downward vertical

The trajectories follow by simple integration of the velocity components over time :

$$
S=\int_{0}^{t} u d t
$$

As an example in Fig.16 the horizontal and vertical trajectories of hollow droplets with an internal gas volume of $20 \%$ have been calculated for the case of an initial velocity of $200 \mathrm{~m} / \mathrm{s}$ under an angle of 60 degrees with the downward vertical. The air is assumed to have a uniform downward velocity of $.532 \mathrm{~m} / \mathrm{s}$. It is clear that the smaller droplets have a much shorter deceleration path than the larger ones.

In reality the trajectories will be much more complicated; one may expect that the deceleration path is longer because of the air flow induced by the atomisation itself. However for first estimates and for comparison of situations this approximation has proved to be a useful tool. 


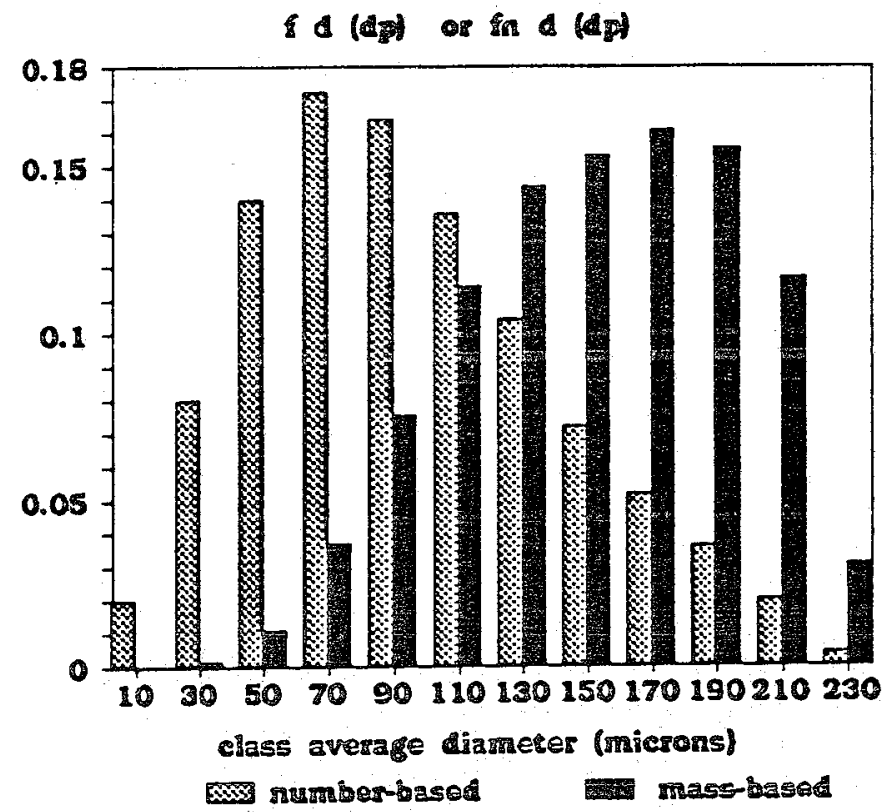

Fig.17. Number and mass based frequency distribution of droplet sizes for calculation example

integration example

As treated in the foregoing, there are a number of more or less complex methods to estimate drying rate, aroma loss, thermal degradation and trajectories for single particles. In order to illustrate the integration of the methods we made an example calculation of a drier with a diameter of $9 \mathrm{~m}$ and a height of $16 \mathrm{~m}$, in which $5000 \mathrm{~kg} / \mathrm{hr}$ of skim milk was to be made with a moisture content of $7 \%$. We assumed an initial droplet size distribution as given by Masters [21] as an example. This number based distribution was calculated into a mass based distribution, as given in Fig. 17. Now assuming disk atomisation with an initial velocity of $200 \mathrm{~m} / \mathrm{s}$, the vertical trajectories were calculated vs. time of flight, as given in Fig. 18. From this graph the residence times of the particles could be estimated for the specified height. Also the drying times for the specified air conditions were calculated as a function of moisture content, as presented in Figs. 19a and 19b. So for each particle class the moisture content followed from its 


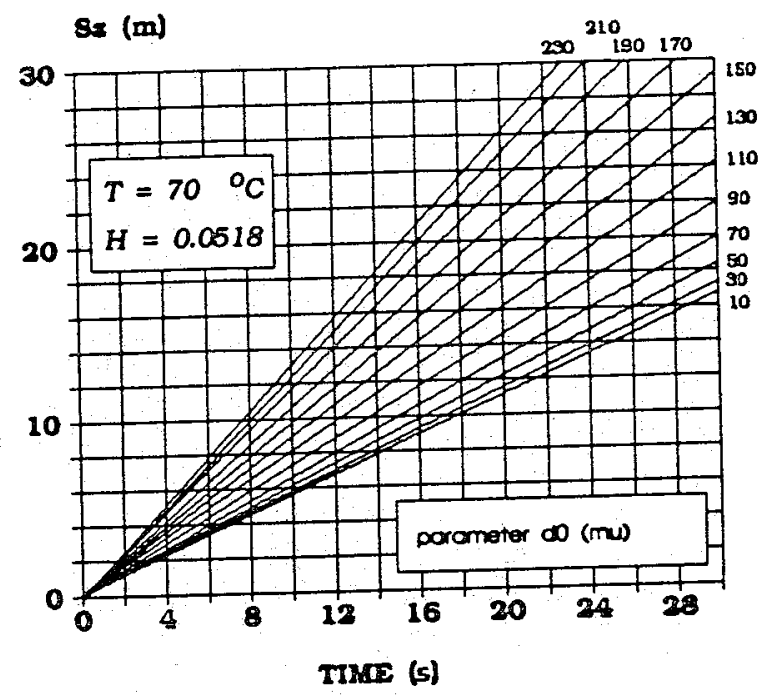

Fig.18. Vertical trajectories calculated as single particie behaviour, initial velocity $200 \mathrm{~m} / \mathrm{s}$ at 0 deg angle with downward vertical

residence time. We also assumed for the case of this example that some thermal degradation reaction would occur, corresponding to that treated in the previous chapter. Both the water content and the rest activity were then integrated over the whole distribution. The individual class results, together with the mass averaged values are shown in Fig. 20. It is clear that in this type of distribution the higher moisture content in the larger classes leads to a moisture content well above the equilibrium value. Due to the zero rest activity in the larger particles also the average activity is very low.

\section{BATCH FLUIDISED DRYING OF BIORRODUCTS}

Effective heat and mass transfer coefficients

The basic well-known model is that of a bed in which the particles are ideally mixed, through which the air flows in plug flow, as has been used by Zimmermann [22] and 


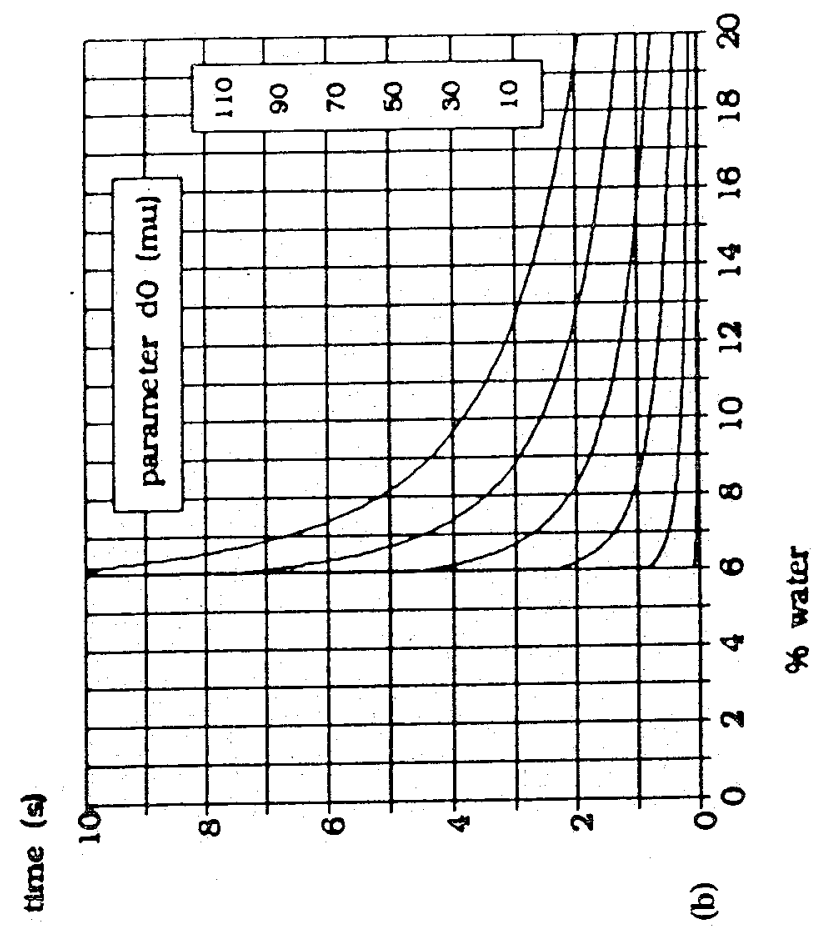

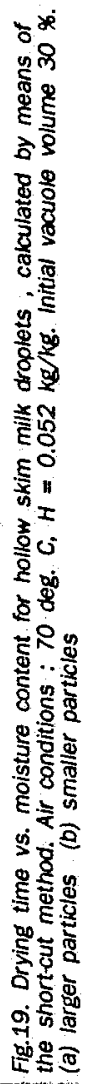

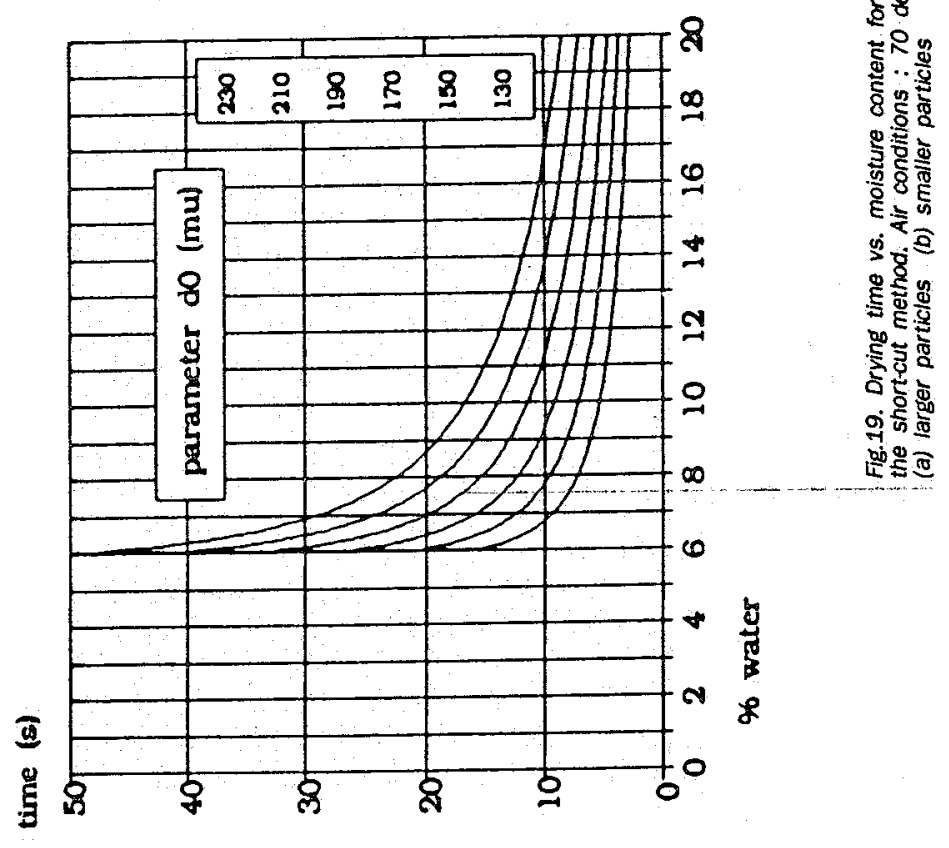




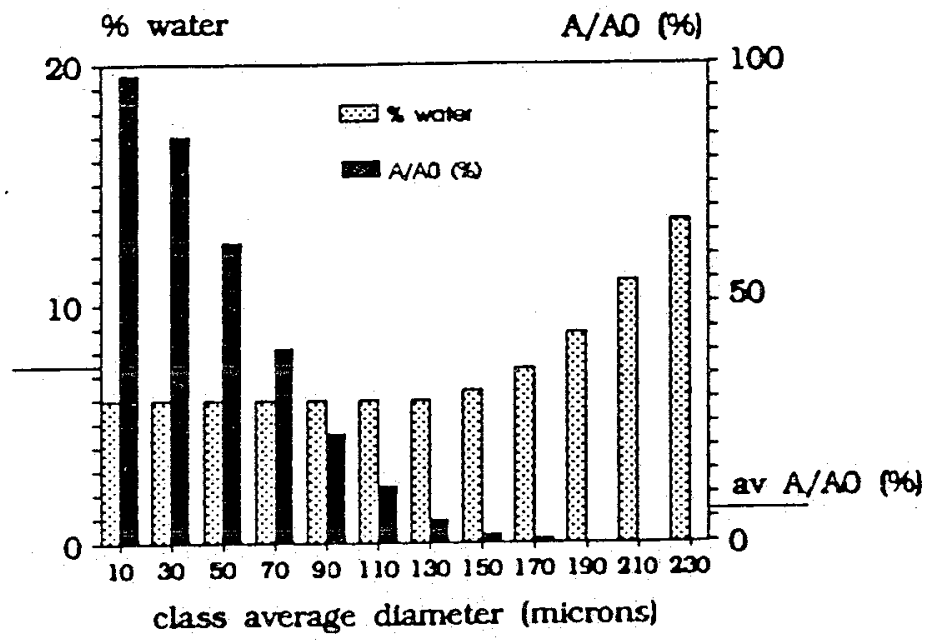

Fig.20. Distribution of final moisture content and rest activity over the droplet size distribution, together with mass averaged values

Strumillo [23], and illustrated in Fig.21. In a very thorough study Lievense et al $[24,25,26$ ] recently described drying and inactivation kinetics of pellets of a mixture of Lactobacillus. Plantarum and starch. It was thought of some interest also for educational purposes to translate their findings from laboratory experiments into considerations for large scale design. For the sake of the example no attention was paid here to the question of drying during filling of the bed, as would have to be taken into account in practice.

Differential balances over the drying air

Following the assumption of an ideally mixed particle bed we asume that we may approximate the surface water concentration and the particle temperature by average values over the whole bed. From a differential height element we have the balances over the air :

$V \frac{d H}{d z}=k_{g, l o c} \rho_{f}\left(H_{i}-H\right) a_{p}\left(1-\varepsilon_{b}\right) A_{b}$ 


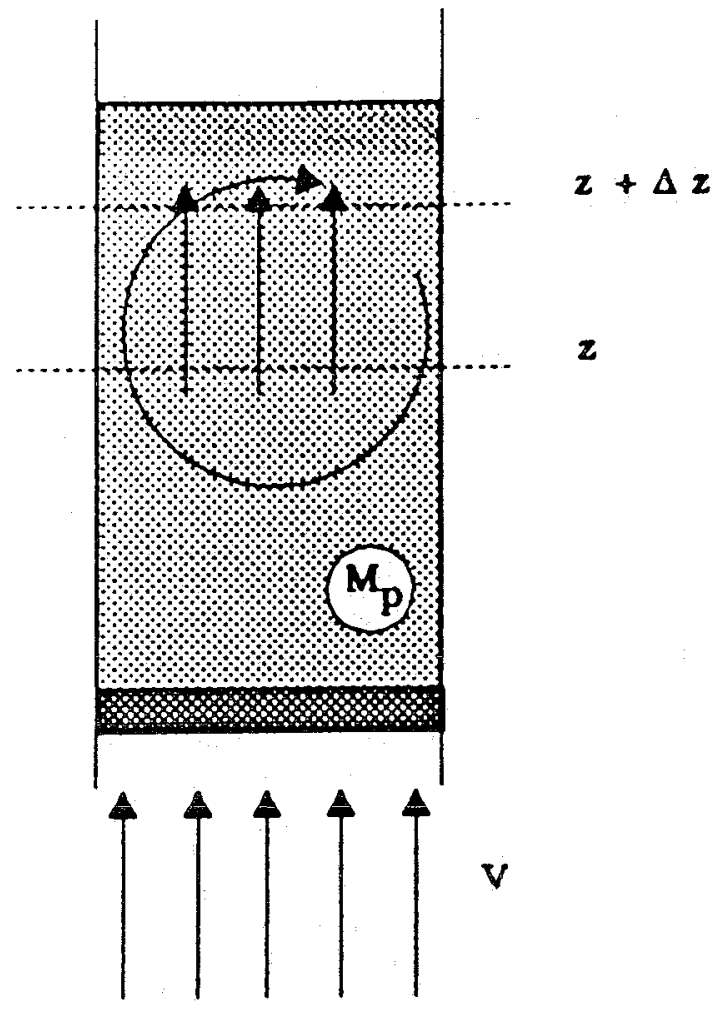

Fig.21. Diagram of batch fluidized bed drier, with air flowing through in plug flow and solids ideally mixed

$$
v \frac{d i}{d z}=\left[\alpha_{l o c}\left(T-T_{a i r, z}\right)+k_{g, l o c} \rho_{f}\left(H_{i}-H\right) i_{v}\right] a_{p}\left(1-\varepsilon_{b}\right) A_{b}
$$

in which $a p$ is the specific area of the particles $\left[\mathrm{m}^{2} / \mathrm{m}^{3}\right], \rho_{\mathrm{f}}$ is the film density of the air $\left[\mathrm{kg} / \mathrm{m}^{3}\right], \varepsilon_{b}$ and $A_{b}$ are the bed porosity and diameter respectively. The coefficients $k_{g, l o c}$ and $\alpha_{\text {loc }}$ are the local mass and heat transfer coefficients $[\mathrm{m} / \mathrm{s}]$ and $\left[\mathrm{kW} / \mathrm{m}^{2} \mathrm{~s}\right]$ respectively. The enthalpy of the created water vapour is denoted by $i_{v}$. The particle temperature is denoted by $\mathrm{T}$. 
By using the psychrometric relationship :

$i=\left(c_{a}+c_{v} H\right) T_{\text {air }}+H \Delta h_{v}$

in which $c_{a}$ and $c_{v}$ are the specific heats of air and vapour respectively, and some approximations we may derive an approximation for the air temperature. Introducing the number of thermal transfer units $N_{t h}$ and the number of mass transfer units $N_{t m}$ according to the following definitions :

$N_{t h}=\frac{\alpha_{l o c}{ }_{p} M_{p}}{\rho_{p} V c_{a, a v}}=\frac{\alpha_{l o c} A_{p t}}{V c_{a, a v}} \quad N_{t m}=\frac{k_{l o c}{ }_{p} \rho_{f} M_{p}}{\rho_{p} V}=\frac{k_{l o c} \rho_{f} A_{p t}}{V}$

and the dimensionless bed height $\xi=\mathrm{z} / \mathrm{L}$

we may derive for the humidity and temperature of the drying air :

$H \cdot H_{i}=\left(H-H_{i n}\right) \exp \left[-N_{\text {tm }} \xi\right]$

$\mathrm{T}_{\text {air }}-\mathrm{T}=\left(\mathrm{T}_{\text {air,in }}-\mathrm{T}\right) \exp \left[-\mathrm{N}_{\text {th }} \xi\right]$

In the above $A_{p t}$ is the total exchange area in the bed.

Effective heat and mass transfer coefficients around the particle

From considerations of a particle which is exposed to random surrounding conditions it follows that effectively the mass and heat transfer rate may be approximated by that obtained by taking the height averaged driving forces over the bed. We may write the average fluxes by relating the driving force to the bed entrance conditions :

$$
\begin{aligned}
& \mathrm{j}_{\mathrm{q}}=\alpha_{\text {eff }}\left(\mathrm{T}_{\text {air,in }}-\mathrm{T}\right) \\
& \mathrm{j}_{\mathrm{w}}=\mathrm{k}_{\mathrm{g}, \text { eff }} \rho_{\mathrm{f}}\left(\mathrm{H}_{\mathrm{i}}-\mathrm{H}_{\text {in }}\right)
\end{aligned}
$$


Applying this we find for the effective transfer coefficients :

$$
\begin{aligned}
& \alpha_{\text {eff }}=\alpha_{\text {loc }} \frac{1}{N_{t h}}\left[1-\exp \left(-N_{t h}\right)\right] \\
& k_{g, \text { eff }}=k_{g, \text { loc }} \frac{1}{N_{t m}}\left[1-\exp \left(-N_{t m}\right)\right]
\end{aligned}
$$

For the local heat transfer coefficient we use the relation of Nelson and Galloway [27] :

$\mathrm{Nu}_{\mathrm{loc}}=\frac{\alpha_{10 c} d_{p}}{\lambda_{\mathrm{air}}}=\frac{2 \varphi+\left\{\frac{2 \varphi^{2}(1-\varepsilon)^{1 / 3}}{\left[1-(1-\varepsilon)^{1 / 3}\right]^{2}}-2\right\}}{\varphi}$

in which $\varphi=0.3\left[\frac{1}{(1-\varepsilon)^{1 / 3}}-1\right] \operatorname{Re}^{1 / 2} \mathrm{Pr}^{1 / 3}$

The local mass transfer coefficient follows from the Chilton - Colbum analogy :

$k_{g, l o c}=\frac{\alpha_{l o c}}{\rho_{f} c_{p f}}(L e)^{-0.33}$

in which Le is the Lewis number Le $=\mathrm{Sc} / \mathrm{Pr}$.

In the foregoing $d_{p}$ is the effective particle diameter. For cylindrical pellets this is equal to :

$d_{p}=\frac{3}{2} \frac{\beta}{(\beta+0.5)} d_{c}$

with $\beta=d_{c} / L_{c}$, the ratio of the cylinder diameter and length.

\section{Fluidisation characteristics}

For the minimum fluidisation velocity we use the relation of Davidson and Harrison [28] :

$\operatorname{Re}_{\mathrm{mf}}=25.7\left[\left[1+5.53 \times 10^{-5} \mathrm{Ga}\right]^{1 / 2}-1\right]$

with $G a=\rho_{f} \Delta \rho g d_{p}^{3} / \mu_{f}^{2}$, the Galilei number. 
For the relation between bed porosity and acrual air velocity we approximated the results reported by Keey [29] :

$\varepsilon=1-0.65 \exp \left[-0.27 \mathrm{u} / \mathrm{u}_{\mathrm{mf}}\right]$

Internal mass transfer and equilibrium

As reported by Lievense the mass transfer can well be described by means of an effective diffusion coefficient, dependent on water concentration and temperature :

$\mathrm{D}=1.5 \times 10^{-10} \mathrm{X}^{1.1066} \exp \left[-3404.9\left[\frac{1}{\mathrm{~T}_{\mathrm{abs}}} \cdot \frac{1}{303.15}\right)\right]$

From estimations of the thermal Biot-number follows that the temperature gradients inside the particle can be neglected.

For the water vapour sorption isotherm he reports the G.A.B. isotherm :

$\frac{X}{X_{m}}=\frac{C k a_{w}}{\left(1-k a_{w}\right)\left(1-k a_{w}+C k a_{w}\right)}$

with $\mathrm{X}_{\mathrm{m}}=0.0794 \mathrm{~kg} \mathrm{H} \mathrm{H}_{2} \mathrm{O} / \mathrm{kg} \mathrm{ds}, \mathrm{C}=28.0, \mathrm{k}=0.859$

\section{Simulation results}

Lievense et al. solved the diffusion equation (4-3) for infinite cylindrical particles by means of the power-law short-cut calculation method of Liou and Coumans. They assumed a very short constant activity period, and so immediately started the calculation for the Penetration Period and subsequently the Regular Regime. They assumed virtually immediate temperature equilibrium between the $1 \mathrm{~mm}$ particles and air. This was justified in their situation, because in the lab drier they used a very small amount of product (10 g.) and a large airflow $(50 \mathrm{~kg} / \mathrm{hr}$ ). Consequently they had a low $\mathrm{nr}$. of transfer units and thus relatively high transfer coefficients : $N_{t h}=0.93, N_{t m}=0.99$, leading to $\alpha_{\text {eff }}=$ $0.24 \mathrm{~kW} / \mathrm{m}^{2}{ }^{\circ} \mathrm{C}$, and $k_{\text {eff }}=0.22 \mathrm{~m} / \mathrm{s}$. 


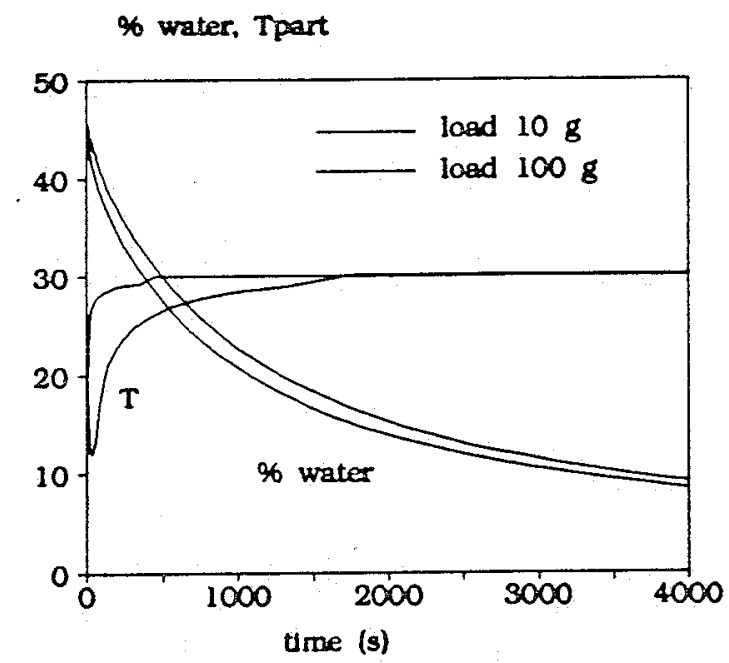

Fig.22. Moisture content and temperature of granules of $L$. plantarum during laboratory fluidized bed drying, for different bed loads

Since their primary aim with the lab experiments was to obtain data for the drying kinetics, it was of interest to see to what extent a drying curve would be influenced by the bed load. We solved the diffusion equation by means of a modified Crank-Nicholson scheme, together with the enthalpy balance for the particles. In Fig. 22 the drying curves are given for the lab drier, for loads of 10 and of $100 \mathrm{~g}$. It is clear that for the small load the temperature rise is virtually immediate, while for the larger load it takes considerably longer. The drying rate for the larger load is somewhat smaller. From this can be seen that the theoretical model is a very useful tool in deciding upon experimental design!

It is clear that in practice one wants to make optimal use of the drying air. Thus the bed loads will be much higher that in the lab. A simulation was therefore also done with a bed load of $1000 \mathrm{~kg}$, for a bed with a diameter of $3 \mathrm{~m}$, and an air flow rate of $50000 \mathrm{~kg} / \mathrm{hr}$. Again the air temperature for the example was taken to be $30^{\circ} \mathrm{C}$. In Fig. 23 we see that the drying curve is dramatically different in shape from that in the lab drier. The temperature first drops and rises only very slowly. This is caused by the much 


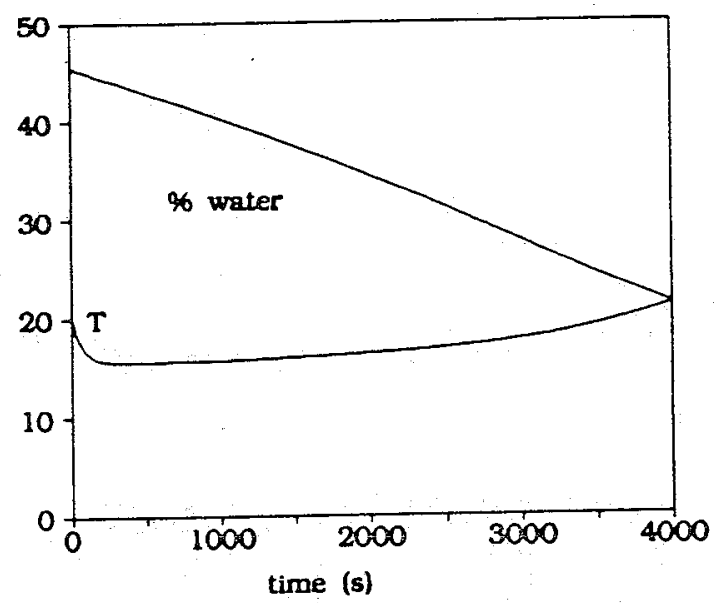

Fig.23. Predicted moisture content and temperature during fluidized bed drying on large scale for a bed load of $1000 \mathrm{~kg}$
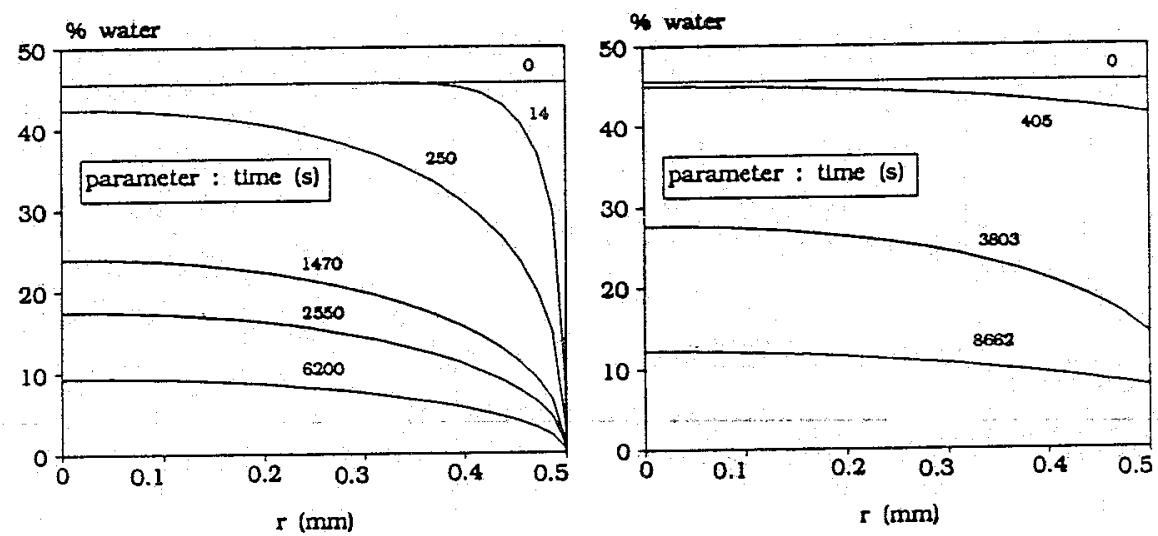

Fig 24. Water concentration profiles inside drying particles of $L$ planetarum as calculated by solving the diffusion equation. Left figure: laboratory drier with $10 \mathrm{~g}$. had, right figure : large scale fluid bed, $1000 \mathrm{~kg}$ 
higher number of transfer units : $\mathrm{N}_{\text {th }}=50, \mathrm{~N}_{\text {tm }}=53$, leading to very low effective heat and mass transfer coefficients of $0.004 \mathrm{~kW} / \mathrm{m}^{2}{ }^{\circ} \mathrm{C}$ and $0.0035 \mathrm{~m} / \mathrm{s}$ respectively.

To illustrate the differences further, we have plotted in Fig. 24 the internal moisture concentration profiles. For the lab situation we see very steep concentration profiles, for the full scale drier they are much more shallow. Clearly the mass transfer limitation has shifted from fully within the particle to a much more pronounced influence of the external resistance. To return to the discussion in the beginning of this paper : for the lab drier the modified Bi-number can be estimated to be 300 , while for the full scale it is about 4.

Since inactivation of microorganisms locally inside the pellets is determined by the local drying and temperature history; the overall effect may be expected to be considerably different for lab and full scale drying.

\section{CONCLUDING REMARKS}

In the foregoing we have implicitly adressed modelling aspects on three levels : physical, mathematical and simulation models. In conclusion the relevance of these types of modelling for scale-up will be summarized in the following.

Physical modelling, setting up an explicit picture of the (sub) processes going on in the drying processes in the lab and full scale, is probably the most important step of all. It provides a framework for communication between various parties involved in the field of scale-up, and urges them to formulate insight into the process. This in itself, combined with some estimations of the magnitude of effects in different situations, may already improve scale-up practice and drying operations.

Mathematical modelling, the translation of the various physical ideas into quantifiable rules, is the key between reasoning and robust predictions. It requires the application of sound engineering principles, and defines what quantities and relationships should be looked for either in literature or from experiments. It also gives insight into the combinations of process variables, and in some cases even without any calculations at all similarity analysis may lead to scale rules. From the diffusion equations with boundary conditions it follows for instance that one would expect only a very small influence of droplet size on aroma retention, but a dramatic effect on thermal degradation $[8,18]$. 
In simulation models the foregoing modelling techniques are put to work. With the modem 386/387 PC's it has become possible to attack a lot of the complex non-linearities in a very rigorous way in a few minutes of calculation time. Combining the calculation models with the very user-friendly graphic programs has opened the possibility of making various phenomena visible, and study the effect of scale and of process variables, as has been shown in the examples. As has been done in the chemical industry for decades, also in drying operations first simulations can be performed before buying or designing equipment. Although good physical data are needed for a proper description, already a lot can be learned from simulations of the drying behaviour of analoge materials.

An essential element is that PC - programs are easily transferred. Although this may incidentally lead to use without full understanding, if combined with a proper description it has the great advantage of opening up the possibilities of simulation for a wider public. Thus the incorporation of complex phenomena in scaling up can be more and more implemented in daily practice.

\section{References}

1. Kerkhof, PJ.A.M. \& Coumans, W.J., (1990), IDS '90, Prague

2. Ketelaars, A.A.M., Coumans, W.J. \& Kerkhof, PJ.A.M.,(1992), to be presented at IDS'92

3. Andrieu, J., Bouvin, M. \& Stamatopoulos, A., (1988), in "Preconcentration and Drying of Foods", ed. S. Bruin, Elsevier, 183 - 192

4. Menting, L.H.C., Hoogstad,B. \& Thijssen, H.A.C., (1970), JFood.Technol, 5, 127

5. Rulkens, W.H. \& Thijssen, H.A.C., Trans.Inst.Chem.Engrs., 47, T292

6. Chandrasekaran, S.K. \& King, C.J., (1972), AIChEJ, 18, 520

7. van der Lijn, J., (1976), Ph.D. Thesis, Agricultural University of Wageningen

8. Kerkhof, PJ.A.M. \& Schoeber, W.J.A.H., (1974), in "Advances in Preconcentration and Dehydration of Foods", Ed. A. Spicer, Appl.Sci.Publ., London, 349

9. Wijthuizen, A.E., Kerkhof, P.J.A.M. \& Bruin, S., (1979), ChemEngng, Sci, 34, 651

10. Coumans, WJ., Kerkhof, P.J.A.M. \& Bruin, S., (1991), paper submitted to "Drying Technology"

11. Meerdink, G. \& van 't Riet, K., (1990), paper accepted by J. Food Eng.

12. Lievense,L.C., Verbeek, M.A.M., Meerdink, G. \& van 't Riet, K., (1990), Bioseparation,

$1,161-170$

13. Schoeber, WJ.A.H., (1976), Ph.D.Thesis, Eindhoven University of Technology

14. Liou,J.K. \& Bruin,S., (1982), Int.J.Heat \& Mass Transfer, 25, 1209

15. Coumans, WJ., (1987), Ph.D. Thesis, Eindhoven University of Technology

16. Kerkhof, P.J.A.M., (1975), Ph.D. Thesis, Eindhoven University of Technology

17. Kerkhof, PJ.A.M. \& Thijssen, H.A.C., AIChE Symp. Ser., 73, (163), 33

18. Kerkhof, PJ.A.M., (1977), EFChE - Minisymposium on "Mathematical Modelling in Food Processing", Örenås, 7-9 September

19. Rulkens, W.H. \& Thijssen, H.A.C., (1973), J. Food Technol., 7, 95

20. Kaskas, A., (1964), Diplomarbeit, Technische Uniyersität, Berlin

21. Masters, K., (1985), "Spray Drying Handbook", $4^{\underline{\underline{h}}}$ ed., George Godwin, London 
22. Zimmermann, K. \& Bauer, W., (1987), Chem.-Ing.-Technik, 59, 350-351

23. Strumillo, C., Markowski, A. \& Adamiec, J., (1990), IDS '90, Prague

24. Lievense, L.C., (1991), Ph.D. Thesis, Agricultural University of Wageningen

25. Lievense,L.C., Verbeek, M.A.M., Meerdink; G. \& van 't Riet, K., (1990), Bioseparation, $1,149-159$

26. Lievense,L.C., Verbeek, M.A.M., Taekema, T., Meerdink, G. \& van 't Riet, K., (1991), accepted by Chem. Eng. Sci.

27. Nelson, P.A. \& Galloway, T.R., (1975), Chem.Eng.Sci., 30, 1-6

28. Davidson, JF. \& Harrison, D., (1971), "Fluidisation", Ac. Press

29. Keey, R.B., (1972), "Drying, Principles and Practice", Pergamon Press, Oxford

\section{APPENDIX. REGULAR REGIME AND DIFFUSION DATA}

Regular Regime data for skim milk and maltodextrin solutions have been fitted to the general form

$$
\ln F_{R R}^{*}=a-b\left[\frac{273.15}{T}\right]-\left[\frac{X}{c+X}\right]\left\{d-e\left(\frac{273.15}{T}\right]\right\}
$$

with $\mathrm{T}$ the absolute temperature, and $\mathrm{X}$ the moisture content on dry basis.

It is advised not to exceed the range of $\mathrm{T}>350 \mathrm{~K}$, especially at low moisture concentrations.

Also for the molecular diffusion coefficient of water a similar fit was made :

$$
\ln D=a_{1}-b_{1}\left(\frac{273.15}{\mathrm{~T}}\right)-\left(\frac{\mathrm{x}}{\mathrm{c}_{1}+\mathrm{X}}\right)\left\{\mathrm{d}_{1}-\mathrm{e}_{1}\left(\frac{273.15}{\mathrm{~T}}\right)\right\}
$$

\begin{tabular}{lccccc} 
& a & b & c & d & e \\
\hline skim milk, sphere & 10.49 & 44.81 & 0.12 & 17.23 & 37.46 \\
skim milk, slab & 11.75 & 45.84 & 0.12 & 20.04 & 38.70 \\
md20, sphere & 50.07 & 84.77 & 0.18 & 61.66 & 82.72 \\
md20, slab & 52.44 & 87.47 & 0.18 & 66.27 & 86.24 \\
$D_{\text {skim milk }}$ & 6.49 & -42.99 & 0.12 & 22.86 & 37.64 \\
$D_{\text {md20 }}$ & 39.32 & 77.42 & 0.18 & 63.38 & 80.45
\end{tabular}

Effective aroma diffusion coefficients used in correlation method

For $\mathrm{n}$-alcohols in aqueous maltodextrin solutions $\mathrm{E}_{\mathrm{a}} / \mathrm{R}$ was found to be equal to $5000 \mathrm{~K}^{-1}$; the values of $D_{a}^{0}$ and $f_{a w}$ were found to be : 


\begin{tabular}{lll} 
component & $\mathrm{D}_{\mathrm{a}}^{0}\left(\mathrm{~m}^{2} / \mathrm{s}\right)$ & $\mathrm{f}_{\mathrm{aw}}$ \\
\hline methanol & $1.86 .10^{-4}$ & 5.41 \\
n-propanol & $3.84 .10^{-5}$ & 6.65 \\
n-pentanol & $2.26 .10^{-5}$ & 7.04
\end{tabular}

